\title{
Perspectivas darwinistas sobre la mente y la conducta humanas: alcances, limitaciones e implicancias educativas
}

\author{
Darwinian perspectives on the human mind and behavior: scope, \\ limitations and educational implications
}

\section{Leonardo González Galli}

Universidad de Buenos Aires, Argentina

leomgalli@gmail.com

\begin{abstract}
Resumen
En este trabajo caracterizo las aproximaciones darwinistas a la conducta y mente humanas, especialmente la psicología evolucionista, y analizo las principales críticas que dichas aproximaciones han recibido. A tal fin recurro a la crítica de Jean Marie Schaeffer a la tesis de la excepcionalidad humana y a la perspectiva semántica de las teorías científicas de Ronald Giere. Concluyo que las principales críticas (reduccionismo, determinismo y sesgo ideológico) no son aplicables a la psicología evolucionista en tanto programa de investigación. Concluyo también que no se puede sostener a priori que el enfoque darwiniano no sea aplicable a la mente y conducta humanas. Finalmente discuto algunas implicancias educativas de estos debates.
\end{abstract}

Palabras clave: selección natural, psicología evolucionista, enseñanza de la biología.

\begin{abstract}
In this work I characterize Darwinian approaches to human behavior and mind, especially evolutionary psychology, and analyze the main criticisms that these approaches have received. To this end I resort to Jean Marie Schaeffer's criticism of the thesis of human exceptionality and the semantic perspective of scientific theories of Ronald Giere. I conclude that the main criticisms (reductionism, determinism and ideological bias) are not applicable
\end{abstract}

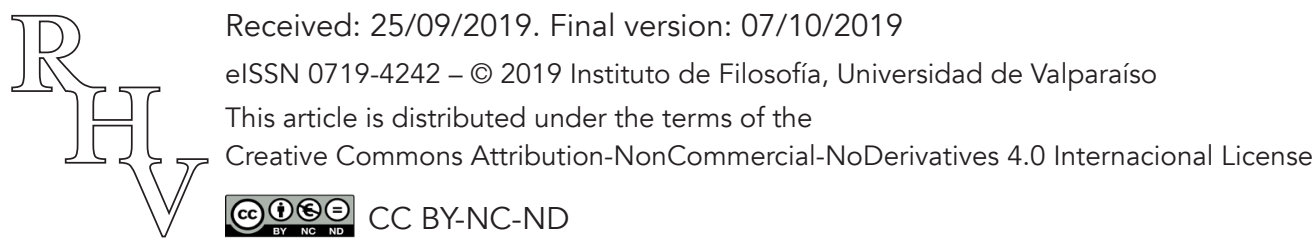


Perspectivas darwinistas sobre la mente y la conducta humanas: alcances, limitaciones e implicancias educativas

Leonardo González Galli

to evolutionary psychology as a research program. I also conclude that it cannot be held a priori that the Darwinian approach is not applicable to the human mind and behavior. Finally, I discuss some educational implications of these debates.

Keywords: natural selection, evolutionary psychology, biology teaching.

\section{Introducción}

La discusión sobre la importancia relativa de los factores biológicos y los socioculturales en la determinación de los rasgos mentales y comportamentales de los humanos es muy antigua. Con frecuencia, el problema se ha planteado en términos dicotómicos ("naturaleza versus crianza", "genes versus ambiente", etc.), y en distintas épocas y contextos el péndulo de las opiniones se movió hacia uno u otro extremo. Tras la segunda guerra mundial la posición antibiológica ${ }^{1}$ ganó fuerza y se estabilizó. Por oposición al "biologicismo" denominaré "socioculturalismo" a dicha postura (Alcock 2001, habla de "determinismo cultural"). En las últimas dos décadas, sin embargo, los avances en diversas áreas de investigación fueron dejando en claro que estos planteos dicotómicos son inconducentes. En este sentido, hay un fuerte consenso sobre el hecho de que tanto los factores biológicos como los socioculturales tienen un rol causal importante. Así, las discusiones de los últimos años versan sobre cómo se produce la interacción entre factores biológicos y ambientales durante el desarrollo. Tal como señaló Steven Pinker hace ya casi veinte años "es posible que el tema naturaleza frente a educación se encuentre agotado" (Pinker 2003, 11).

La preocupación que me motiva a revisitar este tema es que, a pesar de lo dicho en el párrafo precedente, en el ámbito de la educación el péndulo permanece fijo en el extremo antibiológico. Según argumentaré, tal situación obedece a supuestos que son cuestionables y tiene consecuencias que considero negativas. Cuando hablo del "ámbito de la educación" lo hago en un doble sentido. En primer lugar, me refiero al mundo académico de la investigación en didáctica de la biología. En segundo lugar, me refiero al mundo de las prácticas educativas en todos los niveles (especialmente secundaria, profesorados de biología y licenciaturas en biología). En todos estos ámbitos se tiende a asumir un "socioculturalismo" que va de la mano del supuesto según el cual cualquier aplicación de la biología a lo humano ${ }^{2}$ es a priori ilegítima. Más específicamente, los programas de investigación que se basan en la biología para explicar (algunos aspectos de) lo humano reciben tres críticas principales: (1) reduccionismo biológico, (2) determinismo biológico

\footnotetext{
${ }^{1}$ Hablo de posición "antibiológica" y no "antibiologicista" porque si bien la oposición al biologicismo (entendido como la reducción total de lo humano a la biología) está más que justificada, lo que encontramos con frecuencia es una oposición a la aplicación de la biología per se a lo humano.

${ }^{2}$ Utilizaré la expresión "lo humano" para referirme abreviadamente a la mente y la conducta humanas.
}

Revista de Humanidades de Valparaíso, 2019, No 14, 187-222

(c) $(1)(9)$ CC BY-NC-ND 
Perspectivas darwinistas sobre la mente y la conducta humanas: alcances, limitaciones e implicancias educativas

Leonardo González Galli

y (3) sesgo ideológico. Así, la enseñanza suele orientarse a mostrar a los/as estudiantes que la biología no es pertinente para la comprensión de la mente y la conducta humanas y que, por lo tanto, deben sospechar de toda mirada biológica y deben buscar las explicaciones exclusivamente en modelos de las ciencias sociales.

Estas acusaciones han recaído sobre todas las áreas de la biología que amenazan con tener algún valor explicativo para la mente y la conducta. Curiosamente, asumiendo alguna forma de dualismo, se reconoce habitualmente la legitimidad de la biología cuando de la anatomía y fisiología humanas se trata (Soler 2009, 29). Así, la genética, el darwinismo $^{3} \mathrm{y}$, más recientemente, las neurociencias, han sido acusadas de mala ciencia al servicio de los poderosos.

Por supuesto, no se trata de negar aquí el hecho histórico evidente de que muchos han recurrido a la biología (y a otras disciplinas científicas, como la antropología) para justificar un determinado orden socioeconómico (Alexander y Numbers 2010). No se trata tampoco de negar que la ciencia es una empresa humana y que, como tal, está necesariamente atravesada por la ideología. Se trata, en cambio, de elaborar una perspectiva mínimamente sofisticada que evite las falsas dicotomías y la sobresimplificación con que, con demasiada frecuencia, se plantean estas cuestiones. Se trata también de tender a una mejor comprensión de la naturaleza de la ciencia que ayude a entender los alcances y limitaciones de lo que la biología pueda decir sobre estas cuestiones. Es entonces la insatisfacción que como educador e investigador en didáctica de la biología experimento frente a la postura dominante que acabo de caracterizar lo que me motiva a elaborar estas reflexiones.

En este trabajo defenderé la necesidad y legitimidad de las perspectivas biológicas y, más específicamente, darwinistas sobre lo humano (para una introducción general y accesible a este tema puede consultarse Castro, López-Fanjul y Toro 2003). Para tal fin, me serviré de dos ideas de la filosofía de la ciencia que no suelen considerarse en este debate. La primera de estas ideas es la crítica a la "tesis de la excepción humana", desarrollada por el filósofo francés Jean Marie Schaeffer (2009). Tras presentar dicha crítica sugeriré que su aceptación implica rechazar la deslegitimación a priori de las miradas darwinistas sobre lo humano. Además, sostendré que el modo de lidiar con este problema depende fuertemente de qué idea tengamos sobre la naturaleza de las teorías científicas $\mathrm{y}$, más específicamente, intentaré mostrar que la adopción de la denominada perspectiva semántica (esta es la segunda idea a la que recurriré) ofrece una caracterización de las teorías científicas que, en cierto grado al menos, "diluye" buena parte de los problemas asociados a la aplicación de la biología a lo humano. Armado con estas dos ideas abor-

\footnotetext{
${ }^{3}$ Con el término "darwinismo" me referiré al enfoque teórico de la actual biología evolutiva que asume que el principal mecanismo evolutivo es la selección natural.
} 
Perspectivas darwinistas sobre la mente y la conducta humanas: alcances, limitaciones e implicancias educativas Leonardo González Galli

daré las respuestas a las habituales acusaciones de reduccionismo, determinismo y sesgo ideológico. Finalmente, discutiré algunas implicancias de estos análisis, volviendo a mis preocupaciones educativas.

\section{Crítica del excepcionalismo humano y perspectiva semanticista de las teorías científicas}

\subsection{Crítica de la perspectiva excepcionalista sobre el ser humano}

¿Cómo es posible que los avances importantes en el conocimiento del ser humano aportados por la biología [...] no hayan sido acogidos por todos los investigadores en ciencias sociales ni por todos los filósofos y los investigadores en el campo de los hechos culturales [...] como algo que volvía factible el desarrollo de un modelo integrado del estudio de lo humano?

Schaeffer $(2009,14)$

Según Schaeffer (2009), la "tesis de la excepción humana" se compone de cuatro afirmaciones. De acuerdo con la primera, existe una diferencia de naturaleza entre el humano y el resto de los seres vivientes. Se postula así una ruptura óntica al interior de lo viviente. Esto supone más que afirmar que hay rasgos propios del humano (una afirmación más bien trivial, ya que vale para cualquier especie), supone, en cambio, afirmar que en su mismo ser el humano es irreductible a la vida animal como tal. La segunda afirmación, implica una particular interpretación del dualismo ontológico para postular la existencia de dos planos del ser: el material y el espiritual. Esto constituiría una suerte de segunda expresión de la ruptura óntica, pero en este caso al interior de lo humano. La tercera afirmación radica en una concepción gnoseocéntrica del humano, de acuerdo con la cual lo que hay de propiamente humano en nuestra especie es la capacidad de conocer. Finalmente, la cuarta afirmación consiste en el ideal cognitivo anti-naturalista, de acuerdo con el cual el conocimiento de lo que es propiamente humano exige una vía de acceso y un tipo de conocimiento radicalmente diferentes de aquellos que nos permiten conocer las demás entidades. Tanto las ciencias naturales como las sociales son igualmente deslegitimadas por este ideal: ambas adoptan la vía cognitiva externalista ${ }^{4}$ (así, aunque las ciencias sociales suelen declararse anti-naturalistas solo serían anti-biologicistas).

Schaeffer dedica su libro a cuestionar todos los componentes de esta tesis. Por razones de espacio no me extenderé sobre dicha crítica y remito al lector a dicho texto para profundizar en esta cuestión. Me limitaré a señalar aquí que, con respecto a la prime-

\footnotetext{
${ }^{4}$ En este contexto, el externalismo se refiere al modo objetivista de indagar el mundo, "en tercera persona", propio de las ciencias (tanto sociales como naturales). La tesis de la excepción humana, por el contrario, sostiene que el conocimiento de lo que es propiamente humano reclama un tipo de conocimiento radicalmente distinto del que nos permite conocer a todas las demás entidades naturales (incluidos los seres vivos no humanos). Este rechazo del externalismo lleva a un ideal cognitivo antinaturalista.
}

Revista de Humanidades de Valparaíso, 2019, No 14, 187-222

(c) $(1)(9)$ CC BY-NC-ND 
Perspectivas darwinistas sobre la mente y la conducta humanas: alcances, limitaciones e implicancias educativas

Leonardo González Galli

ra afirmación, la aceptación del evolucionismo implica un rechazo de la ruptura óntica. En relación con la segunda afirmación, resulta evidente que una perspectiva basada en las ciencias naturales implica el rechazo del dualismo cuerpo/mente. La tercera afirmación pierde importancia cuando se rechaza la primera: la cuestión de en dónde reside la "esencia humana" solo tiene sentido dada la aceptación de la ruptura óntica. Rechazado dicho supuesto, desde una perspectiva biológica (que no es la única posible y que debería complementarse con otros enfoques), solo se puede discutir qué rasgos tiene el humano en tanto especie biológica, análisis que vale por igual para cualquier otra especie. De hecho, el enfoque evolucionista cuestiona toda mirada esencialista (Mayr 2006): no existe tal cosa como la "esencia humana" (pero, como veremos más adelante, esto no implica negar la existencia de una "naturaleza humana"). Finalmente, en relación con la cuarta afirmación, dado que lo que aquí pretendo es defender la legitimidad de un particular programa de investigación de la biología es claro que asumo una perspectiva externalista y naturalista sobre el humano.

Las críticas a la validez de la perspectiva darwinista de lo humano asumen la primera afirmación (ruptura óntica) y, en ocasiones, parecen asumir también la segunda (dualismo ontológico). En efecto, estas críticas se basan en una perspectiva rupturista según la cual la aparición, en algún momento de nuestra evolución, de la cultura habría vuelto irrelevante el sustrato biológico del que dicha cultura emergió. Esta es la postura expresada en el llamado "modelo estándar de las ciencias sociales", según el cual la cultura es un sistema autónomo, causalmente independiente del sustrato cognitivo y biológico de las mentes individuales (Pinker 2003, 112) ${ }^{5}$. Así, tal como hacía el conductismo, el "socioculturalismo" solo reconoce como biológicamente dado un sustrato psicofísico que otorga al desarrollo de la mente y la conducta una flexibilidad virtualmente ilimitada. Esta perspectiva ha sido denominada "tabla rasa" (Pinker 2003). Debe quedar claro que es perfectamente legítimo, y eventualmente muy útil, desarrollar modelos de solo consideran los factores socioculturales; no cuestiono la validez de dichos modelos sino la censura a priori de aquellos modelos que se centran en los factores biológicos. En este sentido, desde el punto de vista científico, no hay margen para dudar del origen evolutivo de los humanos, y esto supone una tesis fundamental de continuidad: lo que somos no es más que la última versión de un linaje, producto de un proceso de cambio continuo a partir de alguna versión de primate anterior. Así, si aceptamos que en los demás animales operan ciertos factores causales, el supuesto de partida (que, desde ya deberá luego validarse empíricamente) debe ser que dichos factores causales operarán también en nosotros. De modo análogo, si ciertos modelos científicos han probado ser muy iluminadores en relación con algunos aspectos de la conducta de los animales no humanos, el supuesto de

\footnotetext{
${ }^{5}$ Un enfoque como este es legítimo y puede resultar muy fructífero. El problema es que dicho enfoque (o cualquier otro) se proponga como totalizador y excluyente. Lo que sugiero es que, en línea con la mirada perspectivista adoptada en este trabajo, este enfoque centrado en lo sociocultural debería ser parte, junto con otros que aporten otras perspectivas, de un marco general de pluralismo teórico.
}

Revista de Humanidades de Valparaíso, 2019, No 14, 187-222

(c) $(1)(9)$ CC BY-NC-ND 
partida debería ser que dichos modelos también podrían, en principio, iluminar algunos aspectos importantes de nuestra conducta. En este sentido, como veremos, la sociobiología (SB) y la psicología evolucionista (PE) no son más que la aplicación al humano de un programa de investigación cuyo valor explicativo para los animales no humanos es innegable. El poder heurístico y explicativo de este enfoque es notable, y solo una severa confusión entre lo que es y lo que debería ser (según los ideales epistémicos de ciertos autores) podría llevar a negar este hecho que queda en evidencia en la ingente producción académica del área y la resolución (desde ya, nunca total ni definitiva) de algunos viejos enigmas teóricos (Alcock 2001; Carranza 2016; Davies, Krebs y West 2012).

Lo que aquí estoy defendiendo es la legitimidad de los enfoques darwinistas. Esto no supone la defensa de ninguna de las hipótesis específicas sostenidas por unos u otros autores. Es más, queda abierta la posibilidad de que, aunque legítimo, el enfoque darwinista resulte -tras una extensa investigación empírica- poco iluminador en relación con los asuntos humanos que nos interesan. Lo importante es que, una vez establecido que no se puede negar a priori la legitimidad del programa de investigación, el valor global de dicho programa, o de cualquiera de sus hipótesis específicas, deberá evaluarse a partir del análisis de datos empíricos, y no a partir de posturas apriorísticas como aquellas basadas en la idea de que, en tanto seres culturales, los factores biológicos son irrelevantes.

Los enfoques darwinistas del comportamiento animal son actualmente una parte importante y bien establecida de la biología evolutiva. Esto se debe al enorme poder explicativo y heurístico de dicho enfoque. Si asumimos una continuidad histórico-evolutiva entre el humano y los demás animales, entonces, la aplicación de estos modelos explicativos a lo humano no debería considerarse a priori ilegítima, incluso debería considerase prometedora. Para decirlo de otro modo, la negación de tal legitimidad debería argumentarse con base en algún hito evolutivo que marcara una discontinuidad flagrante entre el humano y sus antepasados. Habitualmente, la cultura, o algunos de los rasgos cognitivos que la hacen posible (principalmente, el lenguaje), se ha postulado como ese factor de quiebre entre humanos y no humanos. Sin embargo, dicha perspectiva siempre estuvo reñida con la perspectiva evolucionista dominante que desconfía de los "saltos evolutivos". De hecho, la investigación de las últimas décadas sobre la conducta social de animales no humanos, especialmente de los grandes simios, no ha hecho más que socavar aún más dicho enfoque rupturista (Laland y Galef 2009).

Los enfoques que no atienden a lo biológico no asumen necesariamente una postura discontinuista sino que, simplemente, se centran legítimamente en factores socioculturales. La tesis discontinuista sí es asumida, en cambio, por quienes niegan a priori la validez de los modelos biológicos. De acuerdo con lo que sostendré en la siguiente sección, ningún modelo puede dar cuenta de todos los aspectos de un fenómeno, por lo que nada hay de cuestionable en aquellos modelos que se enfocan en los factores socioculturales. Lo que cuestiono es la pretensión de que los modelos que sí consideran lo biológico, en particular aquellos basados en la selección natural, no son a priori, por razones ideológi-

Revista de Humanidades de Valparaíso, 2019, No 14, 187-222 
Perspectivas darwinistas sobre la mente y la conducta humanas: alcances, limitaciones e implicancias educativas

Leonardo González Galli

cas o de otra índole, aplicables a lo humano. Contra dicha pretensión, he sostenido que el evolucionismo en general pone en cuestión la tesis de discontinuidad y excepcionalidad y que, como consecuencia, la aplicación de los modelos evolucionistas a lo humano resulta legítima a priori.

\subsection{La perspectiva semántica de las teorías científicas}

[...] todas las afirmaciones teóricas permanecen perspectivas en el sentido de que se aplican a aspectos del mundo y luego, en parte porque se aplican solo a algunos aspectos del mundo, nunca con total precisión.

Ronald Giere (2006, 15, traducción propia)

Tal como he adelantado, argumentaré que la forma que toma el debate en torno de la SB y la PE depende en gran medida de la concepción de teoría científica que adoptemos. Describiré brevemente la perspectiva semántica de las teorías científicas, más específicamente la denominada "teoría cognitiva de la ciencia" de Ronald Giere (1992; 2006), que constituye una corriente epistemológica específica dentro de la "familia semanticista" (Díez y Moulines 2008).

La perspectiva semanticista parte de la afirmación de que lo importante en una teoría científica es su significado, esto es, qué dice acerca de qué aspectos del mundo. Por contraste, las perspectivas sintácticas enfatizan la importancia de los aspectos formales de la teoría, tales como las definiciones y las fórmulas matemáticas (Díez y Moulines 2008). De acuerdo con esta perspectiva, lo más importante de una teoría son sus modelos. El modelo es una entidad abstracta. Un aspecto fundamental de este enfoque es la afirmación de que los modelos guardan una relación analógica con los sistemas reales que representan. Así, un modelo solo se parece en cierto grado y aspectos al sistema representado. Según Giere, por tal motivo, no tiene sentido preguntarse si un modelo es verdadero o falso. De acuerdo con lo dicho, si adoptamos un concepto fuerte de verdad por correspondencia, todo modelo resultará falso, ya que nunca tendremos un ajuste total entre el modelo y la realidad. Por tal motivo, la cuestión interesante no es si un modelo es verdadero o falso sino si es adecuado o no. Por supuesto, la evaluación de la adecuación solo se puede hacer en función de ciertas metas. Así, desde esta perspectiva, se asume que los modelos se construyen con la intención de intervenir en el mundo de acuerdo con ciertos fines. Y es en función de esos fines que se evalúa la adecuación del modelo.

La adopción de esta perspectiva epistemológica supone renunciar desde el principio a toda pretensión explicativa totalizadora. Tal como señalamos, en el mejor de los casos, un modelo puede reclamar para sí el mérito de iluminar ciertos aspectos del fenómeno de interés. Así, si tomamos, por ejemplo, la agresión intergrupal (guerra), los modelos darwinianos podrán, eventualmente, dar cuenta de ciertos aspectos de dicho fenómeno, pero en ningún caso de su totalidad. Seguramente, algunos aspectos de la guerra podrán ser

Revista de Humanidades de Valparaíso, 2019, No 14, 187-222

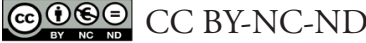


Perspectivas darwinistas sobre la mente y la conducta humanas: alcances, limitaciones e implicancias educativas

Leonardo González Galli

explicados por ciertos modelos de las ciencias sociales. Según los críticos Hilary y Steven Rose (2000), la PE afirma explicar todos los aspectos del comportamiento humano. Aún en caso de que algún psicólogo evolucionista afirmara tal cosa (no me consta), tal pretensión no estaría justificada. Más allá de las eventuales pretensiones de algún investigador particular, un modelo solo estaría, en el mejor de los casos, explicando algunos aspectos del comportamiento humano. Por otro lado, lo que un modelo dice sobre cierto fenómeno siempre es relativo a la perspectiva teórica e instrumental adoptada (perspectivismo). En síntesis, lo que, en nuestro caso, la PE pueda decir sobre lo humano siempre será parcial (iluminará ciertos aspectos y no otros) y perspectivo (solo válido en relación con ciertas perspectivas teóricas y metodológicas adoptadas). Las mismas conclusiones valen para cualquier otro modelo, incluyendo los de las ciencias sociales.

Así, la intención de lograr una comprensión profunda de cualquier fenómeno nos obliga al pluralismo teórico. Tal como discutiré más adelante, muchas discusiones sobre los enfoques darwinianos de lo humano, especialmente la discusión en relación con el problema del reduccionismo biológico, pierden sentido cuando se adopta este enfoque. Espero mostrar que este cambio de perspectiva es de gran valor, sobre todo porque evita enfrentamientos estériles y nos permite concentrarnos en lo que, según creo, debería ser la discusión más interesante: qué modelos explican qué aspectos de los fenómenos de interés.

\section{Perspectivas darwinistas sobre lo humano}

La psicología se basará seguramente sobre los cimientos [...] de la necesaria adquisición gradual de cada una de las facultades y aptitudes mentales. Se proyectará mucha luz sobre el origen del hombre y sobre su historia.

Charles Darwin $(1876,428$, traducción propia)

De acuerdo con el enfoque semanticista adoptado, resulta fundamental enunciar con claridad qué dicen sobre los fenómenos de interés los modelos teóricos en que se basan la $\mathrm{SB}$ y la PE. Intentaré mostrar que si hacemos este ejercicio constataremos que muchas de las críticas que se dirigen contra dichos programas carecen de sustento, simplemente porque atribuyen a estos programas supuestos teóricos que no forman parte de los modelos que los sustentan. Muchas veces, esas críticas se basan en citas acotadas de algún texto de algún investigador particular. Sin embargo, si lo que se pretende es cuestionar un programa de investigación, semejante procedimiento no es adecuado. Los dichos de investigadores individuales pueden ser de interés para un análisis sociológico de la disciplina, pero no para un análisis epistemológico del programa de investigación. Y si la crítica se basa exclusivamente en análisis sociológicos debe tenerse presente que, por más interesantes que sean, dichos análisis son incapaces de evaluar la validez de una teoría.

Revista de Humanidades de Valparaíso, 2019, No 14, 187-222

(c) $(1)(9)$ CC BY-NC-ND 
Perspectivas darwinistas sobre la mente y la conducta humanas: alcances, limitaciones e implicancias educativas

Leonardo González Galli

A continuación, reseñaré los modelos teóricos en que se basan la SB y la PE, procediendo desde los modelos más generales hacia los más específicos.

\subsection{Selección natural y adaptacionismo}

El modelo central común a todos los enfoques darwinistas de la mente y la conducta humanas es, desde ya, el modelo de evolución por selección natural ${ }^{6}$. Comenzaremos, entonces, caracterizando dicho modelo. Siguiendo a Bergstrom y Dugatkin $(2012,60)$ podemos decir que la selección natural es la consecuencia inevitable de tres condiciones:

(1) Variación. Los individuos dentro de la población difieren en sus rasgos.

(2) Herencia. Algunas de las diferencias interindividuales son heredables.

(3) Éxito reproductivo diferencial. Los individuos con ciertas variantes de un rasgo dejan, en promedio, más descendientes que aquellos con otras variantes.

La consecuencia, la evolución por selección natural, es el cambio en la proporción de las diferentes variantes heredables en la población a través de las generaciones.

Este modelo es válido para cualquier rasgo biológico, sea morfológico o comportamental. Muchas personas son reticentes a reconocer la influencia de los genes en la personalidad y la conducta y, por lo tanto, tienden a negar que dichos rasgos puedan evolucionar por selección (Buss 2019; Ridley 2004; Soler 2009). Sin embargo, negar la validez de este modelo para los rasgos conductuales supondría adherir al dualismo que hemos mencionado como parte de la tesis de la excepción humana y que resulta insostenible a la luz de los conocimientos actuales (Plomin et al. 2002) ${ }^{7}$.

Habitualmente, se denominan "adaptaciones" aquellos que rasgos que, por ser producto de la selección, mejoran el ajuste entre el organismo y su medio. El término "adaptacionismo" se utiliza con diversos significados. De acuerdo con Lewens (2007) podemos distinguir:

a. Adaptacionismo empírico: la mayoría de los rasgos son adaptaciones, esto es, son producto de la selección natural.

\footnotetext{
${ }^{6}$ Estrictamente hablando, de acuerdo con la propuesta de Giere, la selección natural sería, por su alto grado de generalidad, más un "principio" que un modelo. A este principio se le agregarían luego algunas condiciones específicas para formular modelos cuya mayor especificidad los haría aplicables a ciertos sistemas reales. Pero estas distinciones no son relevantes para nuestra discusión.

${ }^{7}$ Aquellos modelos sobre la personalidad y la conducta que dejan afuera los factores biológicos no suponen una adhesión al dualismo que estoy criticando. Dichos modelos, simplemente, ponen el foco en otros factores, lo que constituye una decisión perfectamente legítima y potencialmente fructífera. No estoy cuestionando estos modelos: estoy cuestionando el dualismo.
}

Revista de Humanidades de Valparaíso, 2019, No 14, 187-222

(c) $(1)(9)$ CC BY-NC-ND 
Perspectivas darwinistas sobre la mente y la conducta humanas: alcances, limitaciones e implicancias educativas Leonardo González Galli

b. Adaptacionismo metodológico: con independencia de qué tan cierto resulte ser el adaptacionismo empírico, el modo más fructífero de indagar el mundo biológico es asumir hipotéticamente el carácter adaptativo de los rasgos estudiados.

c. Adaptacionismo explicativo: el objetivo más importante de la biología evolutiva es dar cuenta de la adaptación (en este caso "adaptación" se refiere al ajuste entre los organismos y su entorno).

d. Adaptacionismo epistemológico: disponemos de métodos fiables para establecer la validez o no validez de las hipótesis sobre la adaptación.

Los investigadores que se enmarcan en el "programa adaptacionista" adhieren en grado variable a estas diversas formas de adaptacionismo. En cualquier caso, ningún investigador cree, como quiere la caricatura construida por los críticos, que todos los rasgos sean adaptativos. En efecto, cualquier manual de biología evolutiva (Futuyma y Kirkpatrick 2018) deja en claro que existen mecanismos evolutivos no selectivos (la deriva genética, por ejemplo) y que, por lo tanto, siempre está abierta la posibilidad de que el rasgo estudiado no constituya una adaptación. Como programa de investigación el adaptacionismo ha sido criticado (Gould y Lewontin, 1979) y defendido con igual fervor (Dennett 1995). En cualquier caso, incluso los principales críticos del programa adaptacionista reconocen la importancia del concepto de adaptación (Lewontin 1978). En la actualidad un gran porcentaje de las investigaciones que se llevan a cabo sobre la conducta animal se enmarcan en el enfoque adaptacionista (Carranza 2016; Davies, Krebs y West 2012).

\subsection{Ecología del comportamiento}

De acuerdo con Alcock (2001, 9, traducción propia), la ecología del comportamiento (EC) es "el estudio de las relaciones evolucionarias entre el comportamiento de un animal y su entorno". Buller (2007, 263, traducción propia) la define como "el estudio de cómo el comportamiento permite al animal responder adaptativamente a las condiciones de los ambientes físicos y sociales". Sin embargo, este enfoque no supone simplemente la aplicación del darwinismo al estudio del comportamiento animal, sino que implica algunos otros supuestos teóricos más específicos. Un aspecto teórico central para comprender esta especificidad reside en qué respuesta se dé al denominado problema del altruismo. Se dice que una conducta es altruista, en sentido biológico, cuando reduce el éxito reproductivo de que quien la ejecuta al tiempo que incrementa el de otro individuo (Davies, Krebs y West 2012, 307). La razón por la cual este tipo de comportamientos ha resultado problemático para el darwinismo es que, en una primera lectura al menos, la selección no podría favorecer su evolución.

Después de que el propio Darwin considerara que la selección podía explicar la evolución de la conducta tanto como la de la morfología o fisiología, el primer programa de investigación que buscó analizar la conducta desde la perspectiva de la selección natural,

Revista de Humanidades de Valparaíso, 2019, No 14, 187-222

(c) $(1)(9)$ CC BY-NC-ND 
Perspectivas darwinistas sobre la mente y la conducta humanas: alcances, limitaciones e implicancias educativas Leonardo González Galli

en las primeras décadas del siglo XX, fue la etología de Europa continental, representada por investigadores como Konrad Lorenz y Niko Tinbergen (De la O-Rodríguez y Montoya 2011; Lorenz 1986; Thorpe 1982, Tinbergen 1985). En relación con el problema del altruismo, tanto Darwin como estos primeros etólogos asumieron que este problema podía resolverse mediante el concepto de selección de grupos (Sober y Wilson 2000). La idea básica es que los grupos formados por individuos altruistas tendrían un mayor éxito reproductivo que aquellos formados por individuos egoístas. De este modo, a largo plazo, la conducta altruista podría incrementar su frecuencia en la población. Luego, tuvieron lugar importantes desarrollos teóricos en la etología anglosajona que resultaron en respuestas radicalmente diferentes al problema del altruismo.

A comienzos de la década de 1960, William Hamilton desarrolló el concepto de fitness inclusivo. De acuerdo con este concepto, un alelo (una variante de un gen) que tenga como efecto una conducta altruista puede pasar copias de sí mismo a la siguiente generación mediante la producción de descendientes (fitness directo) o mediante una ayuda a parientes cercanos que resulte en un incremento en la supervivencia o reproducción de dichos parientes (fitness indirecto). El fitness inclusivo de dicho gen sería la suma de su fitness directo y su fitness indirecto (Futuyma y Kirkpatrick 2018, 300 y ss.). De acuerdo con esta teoría, las conductas altruistas deberían ser dirigidas preferencialmente hacia parientes cercanos ("selección por parentesco") (Davies, Krebs y West 2012). Esta perspectiva fue luego popularizada por Richard Dawkins (2017a) como la teoría del "gen egoísta”.

Un segundo hito en esta historia lo constituye la publicación, en 1966, de “Adaptation and natural selection" de George Williams (1966). Además de presentar de un modo más accesible la teoría de Hamilton, y de analizar cómo llevar a cabo el estudio científico de la adaptación, en este libro Williams desarrolló una crítica demoledora de la idea de selección de grupos. Aunque teóricamente posible, la selección de grupos sería una fuerza débil en la evolución, principalmente porque la selección de individuos al interior de cada grupo tendería a favorecer el egoísmo, y dado que la selección de individuos es más rápida que la de grupos, se impondrían las variantes egoístas (este tipo de altruismo no sería "evolutivamente estable"). Posteriormente, Robert Trivers (1971; 1972) desarrolló los modelos de altruismo recíproco, de inversión parental y de conflicto paterno-filial. La primera de estas ideas permitió comprender de qué modo la selección podría favorecer conductas altruistas entre individuos no emparentados.

Estamos ahora en condiciones de definir en qué cosiste la especificidad del enfoque teórico de la EC. Esta corriente teórica puede definirse como una variante del programa adaptacionista, aplicado al estudio del comportamiento animal, basado en los principios desarrollados por Hamilton (fitness inclusivo), Williams (rechazo de la teoría de la selección de grupos) y Trivers (altruismo recíproco, inversión parental, conflicto pater-

Revista de Humanidades de Valparaíso, 2019, No 14, 187-222

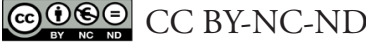


Perspectivas darwinistas sobre la mente y la conducta humanas: alcances, limitaciones e implicancias educativas

Leonardo González Galli

no-filial). Además, la EC ha recurrido a la teoría de los juegos para desarrollar modelos de optimalidad, a partir de los cuales derivar hipótesis específicas sobre cómo deberían comportarse los animales dadas ciertas condiciones (Bautista y Fernández-Juricic 2016).

\subsection{Sociobiología humana}

El hecho de que la SB llegara a tener nombre propio se debe más a cuestiones histórico-sociológicas que a cuestiones conceptuales. El nombre deriva del libro "Sociobiología: la nueva síntesis" que Edward O. Wilson publicó en 1975 (citado aquí como Wilson 1980; Ruse 1980). Dado el clima intelectual y político en Estados Unidos de América a mediados de la década de 1970, el hecho de que Wilson dedicara el último capítulo de su libro a nuestra especie generó un áspero debate. Sin embargo, desde el punto de vista teórico hay poco de original en el libro de Wilson. A pesar de esto, se ha popularizado la idea errónea según la cual la SB es una teoría sobre el comportamiento humano propia de Wilson (Alcock 2001, 5). La definición del propio Wilson $(1980,5)$, según la cual la SB es "el estudio sistemático de las bases biológicas de todo comportamiento social" es engañosamente amplia y oculta algunos rasgos fundamentales del campo, como el hecho de que quienes se autodenominan "sociobiólogos" están invariablemente interesados en analizar las conductas sociales desde el punto de vista evolutivo (causas últimas) y no, por ejemplo, desde el punto de vista fisiológico (causas próximas). Los sociobiólogos estudian la conducta social desde una perspectiva darwinista y, más específicamente, se distancian de la etología clásica europea para basarse en los supuestos teóricos de la EC. Así, la SB podría definirse como la EC aplicada a la conducta social de los animales, incluido Homo sapiens. El término "sociobiología" es muy poco utilizado en la actualidad.

\subsection{Psicología evolucionista}

De acuerdo con Buller (2007, 255 y ss.), la PE constituye un programa de investigación específico que tiene su origen en las obras de los antropólogos John Tooby y Donald Symons y los psicólogos Leda Cosmides y David Buss. Estos autores parten de una crítica a la EC según la cual no sería conveniente estudiar el carácter adaptativo de las conductas. Dado que la conducta es el output de un sistema de procesamiento de información cognitivo operando en cierto entorno no serían las conductas en sí las que fueron seleccionadas, sino, más bien, el sistema de procesamiento de la información. Así, la PE se propone investigar los sistemas cognitivos que generan las conductas, y no las conductas mismas. Para semejante programa de investigación adoptan los siguientes supuestos teóricos. En primer lugar, se asume que la cognición está adaptada al estilo de vida del pleistoceno y no al entorno actual. Desde hace más de un millón de años, y hasta hace apenas unos diez mil años, los humanos vivimos en pequeñas hordas de cazadores-recolectores. Esto no significa, desde ya, que nuestras adaptaciones cognitivas hayan surgido de novo en el

Revista de Humanidades de Valparaíso, 2019, No 14, 187-222

(c) (1) (9) CC BY-NC-ND 
Perspectivas darwinistas sobre la mente y la conducta humanas: alcances, limitaciones e implicancias educativas

Leonardo González Galli

pleistoceno. En efecto, nuestros rasgos cognitivos tienen un origen remoto, es solo que el pleistoceno representa la última etapa de nuestra evolución en que los humanos vivimos al modo ancestral, antes de que la agricultura y otros cambios culturales modificaran rápida y drásticamente nuestro entorno y estilo de vida. Por el poco tiempo transcurrido desde entonces, los psicólogos evolucionistas consideran improbable que hayan evolucionado nuevas adaptaciones cognitivas al estilo de vida posterior al pleistoceno. En segundo lugar, como la supervivencia supone múltiples problemas particulares, es esperable que se hayan seleccionado rasgos psicológicos específicos que resultaran adaptativos en relación con dichos problemas. Dichos sistemas cognitivos adaptativos específicos son llamados "módulos" (Pinker 2000). Los psicólogos evolucionistas tienden a asumir que disponemos de cientos de módulos específicos ("tesis de la modularidad masiva"). Estos módulos serían dominio-específicos, esto es, incluirían una gran cantidad de conocimiento innato sobre cada dominio y surgirían como parte del desarrollo normal. En tercer lugar, se asume que esta arquitectura cognitiva es común a toda la especie. Por último, dado que para la mayoría de los humanos el ambiente actual es radicalmente distinto del entorno ancestral en que se seleccionaron los módulos, no es esperable que las conductas actuales sean en sí mismas adaptativas.

De acuerdo con Buller (2007 269 y ss.), las principales diferencias entre la EC y la PE son: (1) mientras la PE investiga adaptaciones psicológicas al entorno del pleistoceno, la EC humana investiga adaptaciones conductuales a las condiciones ambientales (incluidas las actuales), (2) mientras la PE espera que las conductas sean con frecuencia maladaptativas en los entornos actuales, la EC espera que sean adaptativas, (3) la PE propone que se debe estudiar la adaptación de la mente al entorno pleistocénico, mientras la EC propone que se debe estudiar el ajuste adaptativo de las conductas al entorno actual, (4) mientras la PE sostiene la tesis de la modularidad masiva, la EC permanece agnóstica en relación con el tipo y número de mecanismos psicológicos que causan las conductas y, finalmente, (5) la PE busca investigar una estructura cognitiva universal, mientras que la EC busca estudiar cómo las diferencias ambientales producen diferencias conductuales entre los individuos. En cualquier caso, no es claro en qué medida ambos programas de investigación son compatibles (Buller 2007, 271).

Como ya señalé, el término "sociobiología" está en desuso por haber quedado asociado al nombre y a las particulares opiniones de Edward. O. Wilson. Por esta razón, se suele hablar de EC humano, cuando se analizan las conductas, o de PE, cuando se analizan los mecanismos cognitivos. Para abreviar, de aquí en adelante hablaré directamente de PE, pero mis análisis son igualmente válidos para la EC.

\section{Las críticas}

Se han planteado numerosas críticas a la SB y la PE, entre ellas que estas disciplinas suponen determinismo biológico, reduccionismo biológico, un sesgo ideológico conser-

Revista de Humanidades de Valparaíso, 2019, No 14, 187-222

(c) $(1)(9)$ CC BY-NC-ND 
Perspectivas darwinistas sobre la mente y la conducta humanas: alcances, limitaciones e implicancias educativas

Leonardo González Galli

vador, falencias metodológicas, uso abusivo de analogías, exceso de especulación, hipótesis no refutables (Diéguez 2012, cap. 12). Dado que por cuestiones de espacio es imposible analizar todas estas críticas, me limitaré a discutir las tres acusaciones más frecuentes y más generales: determinismo, reduccionismo y sesgo ideológico. Para sostener sus objeciones contra la PE los críticos suelen recurrir a la metodología de identificar frases específicas que pueden entenderse como la expresión de, por ejemplo, una postura reduccionista. Sin embargo, siempre resulta sencillo encontrar frases que parezcan apoyar prácticamente cualquier postura. En cambio, para juzgar si estas acusaciones tienen o no fundamento, sugiero que es más adecuado examinar los supuestos de los modelos teóricos en cuestión para ver si implican o no lo que se les adjudica. Para tal fin recurriré a libros de algunos de los autores más reconocidos de las disciplinas analizadas.

\subsection{Reduccionismo y determinismo}

La idea de determinismo genético es en gran medida irrelevante, porque nadie adhiere a ella, al menos ningún biólogo evolucionista competente lo hace.

John Maynard Smith (1997, 522, traducción propia)

Dos críticas principales que han recibido todos los enfoques biológicos sobre lo humano es que se trata de perspectivas reduccionistas y deterministas. Un problema no menor es que ambos términos tienen más de un significado, y no siempre es claro cuáles de esos significados están en juego en las críticas en cuestión.

En el caso del reduccionismo existen, al menos, tres significados (Diéguez 2012, 189 y ss.; Dobzhansky et al. 1980, 487 y ss.). En primer lugar, habría un reduccionismo ontológico que supone que todos los aspectos y propiedades de un organismo son producto exclusivamente de la interacción de sus componentes mínimos. Luego, habría un reduccionismo metodológico según el cual la investigación debe orientarse a los niveles inferiores de organización. Finalmente, está el reduccionismo epistemológico o teórico que se refiere a la reducción de una teoría a otra (para una discusión de este complejo asunto véase Díez y Moulines 2008, 391 y ss.), en el que la teoría reducida pasar a ser un caso particular de otra teoría de mayor alcance. Los reduccionismos ontológico y metodológico no son muy problemáticos (al menos para el tema que me ocupa aquí). En relación con el primero, ningún científico sugiere que desde el punto de vista ontológico haya algo más que átomos y otras entidades estudiadas por los físicos y sus interacciones. En relación con el segundo, en qué nivel de organización se pone el foco del análisis es una cuestión pragmática, dada por los objetivos de la investigación. Es el reduccionismo epistemológico, que amenaza con un reemplazo de las ciencias sociales por la biología, el que es más problemático.

Ahora bien, ¿En qué sentido dicen los críticos que la SB o la PE son reduccionistas? Por ejemplo, Lewontin, Rose y Kamin $(1996,16)$ afirman que:

Revista de Humanidades de Valparaíso, 2019, No 14, 187-222

(c) (1) (9) CC BY-NC-ND 
Perspectivas darwinistas sobre la mente y la conducta humanas: alcances, limitaciones e implicancias educativas

Leonardo González Galli

los reduccionistas intentan explicar las propiedades de conjuntos complejos [...] en términos de las unidades de que están compuestas estas moléculas o sociedades [y que] [...] sostendrían que las propiedades de una sociedad humana [...] son la suma de los comportamientos y tendencias individuales de los seres humanos de que se compone esa sociedad. Las sociedades son agresivas, por ejemplo, porque los individuos que las componen son agresivos.

No es claro a qué forma de reduccionismo se refieren estos autores. Pareciera que denuncian alguna forma de reduccionismo metodológico y/o epistemológico que implicaría la desaparición de las ciencias sociales porque, presuntamente, todos los fenómenos sociales podrían explicarse en términos de genes y selección natural. Sin embargo, los psicólogos evolucionistas no se proponen tal reemplazo disciplinar, sino que, más bien, buscan ofrecer explicaciones ancladas en niveles de análisis diferentes de los de las ciencias sociales e, incluso, en ocasiones, intentan conectar esos diversos niveles de análisis (Pinker 2003, 115 y ss.). La PE tampoco supone un reduccionismo que, como el denunciado en la cita de Lewontin et al., niegue la existencia de fenómenos propios de niveles superiores de organización (Dennett 1995, 80 y ss.). Así, es difícil ver que el avance de estas disciplinas biológicas implique una reducción o una sustitución teóricas en relación con las ciencias sociales. Sí es esperable, y seguramente positivo, que tengan lugar influencias recíprocas (Ruse 1980, 235 y ss.).

En cuanto al determinismo ${ }^{8}$, se trata de una doctrina según la cual a iguales condiciones se obtendrán iguales resultados. Presumiblemente, el determinismo genético supone que los genes son los únicos factores causales relevantes y que, por lo tanto, a iguales genes, iguales estructuras cognitivas y conductas. Citemos nuevamente a Lewontin et al. (1996, 16-17):

Esencialmente, los deterministas se preguntan: ¿Por qué son los individuos como son? ¿Por qué hacen lo que hacen? Y responden que las vidas y las acciones humanas son consecuencias inevitables de las propiedades bioquímicas de las células que constituyen al individuo. Por último, todo comportamiento humano $-\mathrm{y}$, en consecuencia, toda la sociedad humana- está regido por una cadena de determinantes que van del gen al individuo, y de éste, a la suma de los comportamientos de todos los individuos. Los deterministas afirmarían, pues, que la naturaleza humana está determinada por nuestros genes.

\footnotetext{
${ }^{8}$ Es frecuente que el miedo al determinismo se vincule con la cuestión del libre albedrío y de la responsabilidad individual: si los genes determinan mi conducta, entonces, yo no puedo ser responsable de mis actos. Sin embargo, este problema atañe a toda forma de determinismo y no solo, ni especialmente, al genético. Así, si creemos que nuestra conducta está determinada por nuestra crianza y nuestra cultura estamos frente al mismo problema. Por lo tanto, señalar que los genes tienen algún poder causal (una de las premisas de cualquier interpretación darwinista) en el desarrollo de nuestra conducta tiene exactamente las mismas consecuencias, en relación con el problema del libre albedrío y de la responsabilidad individual, que señalar que la crianza lo tiene.
}

Revista de Humanidades de Valparaíso, 2019, No 14, 187-222 
Perspectivas darwinistas sobre la mente y la conducta humanas: alcances, limitaciones e implicancias educativas Leonardo González Galli

Esta idea de determinismo genético supone, además, que la existencia de un "gen para X" implica que no es posible eludir el desarrollo de X (Alcock 2001, 41). Por ejemplo, de acuerdo con Stephen Gould (2010, 266): "Si estamos programados para ser lo que somos, entonces estos rasgos constituyen algo ineluctable. En el mejor de los casos, podemos canalizarlos, pero no cambiarlos, ni por medio de la voluntad, ni de la educación, ni de la cultura".

La cuestión del determinismo genético está directamente ligada a la pregunta sobre el rol que los genes cumplen en el desarrollo. Analizaré esta cuestión para concluir que, desde el punto de vista de los modelos científicos vigentes, el determinismo genético es un sinsentido. Dado esto, ni la PE ni ninguna otra disciplina que pretenda ser tenida por ciencia respetable podría asumir el determinismo genético y, de hecho, ninguna disciplina adopta ese supuesto suicida. Además, insistiré en que la PE no asume ninguna forma de determinismo genético porque no precisa de tal supuesto: la PE (el igual que todo el darwinismo) requiere que los genes influyan en el desarrollo de los rasgos, no que lo determinen.

Abordemos entonces la cuestión de qué hacen (y qué no) los genes. Con frecuencia, los psicólogos evolucionistas, al igual que todos los biólogos, utilizan expresiones con la forma "el gen de o para X", siendo X cualquier rasgo fenotípico, incluidos los rasgos conductuales y cognitivos. Lo primero que hay que señalar es que estas expresiones no suponen que $\mathrm{X}$ exista como consecuencia exclusiva de la existencia de dicho gen, es decir, no suponen una relación de determinación. Por ejemplo, la afirmación de que existe un "gen Z para (o de) el color blanco" en una especie de roedor significa que, en promedio, y manteniéndose constantes las demás variables (ambientales y genéticas) que influyen en este rasgo, será más probable que el pelaje sea blanco en aquellos individuos que poseen $\mathrm{Z}$ que en aquellos que poseen un alelo diferente. Sin embargo, la posesión de $\mathrm{Z}$ no supone el desarrollo inexorable del color blanco. Esto se debe a que lo más probable es que la producción del color blanco requiera la concurrencia de otros factores causales (genéticos y ambientales). Así, siempre podría suceder que alguno o varios de dichos factores estuvieran ausentes en el desarrollo de un individuo particular, de modo que ese individuo no desarrollaría el pelaje blanco aún en caso de portar el gen Z. Cabe señalar aquí que, por la mirada que supone de los sistemas biológicos, la genética considerará especialmente relevante el rol causal de los genes, lo que no quita que otras teorías enfaticen el rol de causal de otros factores.

Es importante detenerse en la expresión "en promedio" del párrafo anterior. Esta expresión significa que la afirmación según la cual el gen $\mathrm{Z}$ produce pelaje blanco es una afirmación probabilística, lo que, por definición, excluye relaciones de determinación fuertes. Lejos de ser una curiosa excepción, esto es la norma en la biología. En efecto, dada la multicausalidad implicada en todo sistema biológico solo podemos aspirar a hacer afirmaciones probabilísticas (Mayr 1998, 88). Este aspecto epistemológico de las afirmaciones de la biología es sumamente relevante y suele ser ignorado en este debate. Es

Revista de Humanidades de Valparaíso, 2019, No 14, 187-222

(c) $(1)(9)$ CC BY-NC-ND 
Perspectivas darwinistas sobre la mente y la conducta humanas: alcances, limitaciones e implicancias educativas

Leonardo González Galli

cierto que, con frecuencia, quienes hablan desde la biología no hacen explícito el carácter probabilístico de sus afirmaciones (lo mismo cabe para quienes hablan desde las ciencias sociales). Sin embargo, sería engorroso estar continuamente aclarando el carácter probabilista de las afirmaciones y, además, tal explicitación no debería ser necesaria porque, como dije, no se trata de un curioso aspecto de alguna explicación particular sino de un rasgo de toda explicación biológica.

Siguiendo con nuestro ejemplo, la posesión del gen $\mathrm{Z}$ no supone tampoco que sea imposible modificar el color del pelaje a partir de la manipulación de otros factores causales, incluidos los ambientales. Podría suceder, por ejemplo, que el color del pelaje fuera sensible a la dieta del animal, en cuyo caso cabría la posibilidad de modificar el pelaje manipulando la dieta. Nótese que, aunque un gen (o cualquier otro factor causal) no puede determinar un rasgo, sí puede determinar una diferencia en dicho rasgo. En este ejemplo, aunque la coloración de la piel en el roedor fuera resultado de múltiples factores causales, podría suceder que dos individuos tuvieran distinta coloración solo porque uno de ellos tiene el gen $\mathrm{Z}$ y el otro tiene un alelo alternativo. Del mismo modo, podría ser la dieta lo que explicara la diferencia fenotípica. Y, desde ya, la diferencia en cuestión podría deberse a una compleja interacción de factores causales genéticos y ambientales.

En los análisis de la genética conductual de animales no humanos está claro que el ambiente cumple un rol causal importantísimo en el desarrollo. Por ejemplo, un concepto central de la genética del comportamiento es el de heredabilidad (Plomin et al. 2002, 108 y ss.). Dicho término se refiere a la proporción de la varianza de un rasgo que puede atribuirse a la variabilidad genética subyacente para una dada población y en un momento dado. De más está decir que aquella proporción de la varianza que no es explicada por la variabilidad genética es explicada por la variabilidad ambiental (o por una interacción entre los factores genéticos y ambientales), otro ejemplo de lo evidente y rutinario que es en estos análisis el reconocimiento de la importancia del ambiente. Más específicamente, en la definición de heredabilidad la aclaración "para una dada población y en un momento dado" implica que el efecto de la variabilidad genética detectado solo es válido en un ambiente dado. Esto se debe a que los efectos que un gen tiene sobre un rasgo suelen variar con las condiciones ambientales: es frecuente que existan interacciones genes-ambiente (Sapolsky 2018, 366 y ss.). Los genes influyen, sí, pero el modo en que lo hacen suele depender del ambiente. A esto se refiere Matt Ridley (2004) con la frase — que da título a su libro - "naturaleza por vía del ambiente" (nature via nurture). Del mismo modo, el ambiente influye, sí, pero el modo en que lo hace suele depender de los genes. Por ejemplo, un experimento ya clásico muestra que en ciertas condiciones ambientales cierto genotipo resulta en una mayor "inteligencia" (en realidad, un menor número de errores al resolver un laberinto) en ratas. Sin embargo, en otras condiciones ambientales ese mismo genotipo tiene el efecto inverso: una menor "inteligencia". ¿Influyen los genes en la "inteligencia" de las ratas? Sí, pero el modo en que lo hacen depende del ambiente, a tal punto que en 
Perspectivas darwinistas sobre la mente y la conducta humanas: alcances, limitaciones e implicancias educativas

Leonardo González Galli

ambientes diferentes esos genes pueden tener efectos antagónicos (Plomin et al. 2002, 182). En palabras de Dawkins $(2017 b, 41)$ — un presunto determinista genético, según sus críticos-:

[...] la varianza genética es una causa significativa de una gran parte de la varianza fenotípica en las poblaciones observadas, pero sus efectos pueden ser anulados, modificados, aumentados o invertidos por otras causas [...] Los sucesos ambientales, tanto internos como externos, pueden modificar los efectos de los genes y pueden modificar los efectos de otros sucesos ambientales.

Podemos pensar que existe un continuo en la sensibilidad del desarrollo de los rasgos en relación con la influencia ambiental. En un extremo, algunos rasgos son muy sensibles a dicha influencia (por ejemplo, en nuestra especie, el peso corporal), mientras que, en el extremo opuesto, otros son muy poco sensibles (por ejemplo, el color de ojos). Sin embargo, en cualquier caso, incluido el color de ojos, sería erróneo decir que el rasgo está determinado genéticamente. En relación con esta cuestión, todo etólogo, ecólogo del comportamiento o psicólogo evolucionista sabe que los rasgos cognitivos y conductuales suelen encontrarse cerca del extremo de máxima sensibilidad del desarrollo ante las variables ambientales. Los textos de estas disciplinas declaran explícitamente los múltiples modos en que el ambiente influye en el desarrollo de la mente y la conducta al exponer sus modelos teóricos, y hacen referencia rutinariamente a dicha influencia en sus análisis. Buss (2019, 50-51), por ejemplo, explicita claramente tres modos en que el ambiente ejerce su influencia. En términos evolutivos, fue el ambiente el que determinó qué rasgos se seleccionaron (este no es el punto conflictivo). Además, tanto la emergencia durante el desarrollo individual de cada mecanismo cognitivo como su eventual activación requieren de ciertos inputs ambientales. En el mismo sentido, un concepto importante en EC es el de "estrategia condicional" (Alcock 2001, 157), según la cual los animales poseen sistemas de toma de decisiones que les permiten ejecutar distintas conductas adaptativas según las circunstancias. De este modo, la conducta en sí es producto de la interacción entre las circunstancias ambientales y el sistema cognitivo de toma de decisiones. Una analogía ayuda a transmitir la idea de la imposibilidad de toda forma de determinación, sea genética o ambiental (Harris 2015, 73; Sapolsky 2018, 370). Observemos un rectángulo y preguntémonos si su área se debe a la base o a la altura. ¿Absurdo verdad? Del mismo modo, es absurdo preguntar si un rasgo "es genético" o si "es ambiental". Sin embargo, la diferencia en el área de dos rectángulos podría deberse exclusivamente a una diferencia en la base, exclusivamente a una diferencia en la altura o, desde ya, a una diferencia simultánea en ambas variables (aparentemente, esta analogía se debe al gran neurobiólogo Donald Hebb). Observemos también que esta analogía ayuda a comprender que - contra lo que muchos críticos afirman - los efectos de ambas variables pueden separarse a los fines del análisis (Plomin et al. 2002, 108).

Revista de Humanidades de Valparaíso, 2019, No 14, 187-222

(c) $(1)(9)$ CC BY-NC-ND 
Perspectivas darwinistas sobre la mente y la conducta humanas: alcances, limitaciones e implicancias educativas

Leonardo González Galli

Dado todo lo dicho en los párrafos precedentes, sería realmente curioso que los psicólogos evolucionistas defendieran para el estudio de la conducta humana un enfoque que ningún biólogo se atrevería a defender a la hora de estudiar, por ejemplo, el desarrollo de las estructuras florales de las plantas. El hecho de que el determinismo genético sea un sinsentido biológico hace que esta acusación sea especialmente insostenible (Dawkins 2017 b, 35 y ss.). En síntesis, es ya un lugar común señalar que cualquier rasgo biológico es producto de un proceso de desarrollo en el que influyen tanto factores genéticos como ambientales (De Waal 2000; Harris 2015; Meaney 2006; Plomin et al. 2002; Ridley 2004; Sapolsky 2018; 2007).

El punto importante para nuestra discusión es que los psicólogos evolucionistas o los ecólogos del comportamiento no sostienen ninguna hipótesis idiosincrática en relación con la cuestión de cómo influyen los genes en el fenotipo. Por el contrario, asumen los conocimientos estándar, bien establecidos y poco problemáticos sobre qué son los genes y qué hacen. Cuando los investigadores de estas disciplinas afirman, por ejemplo, que la tendencia a dirigir los actos altruistas preferentemente hacia parientes cercanos es producto de la selección natural están asumiendo que ha existido variabilidad heredable para dicho rasgo. Es decir, se asume que han existido diferentes alelos que producían una diferencia estadística, entre los individuos que tenían uno u otro alelo, en la tendencia a preferir a los parientes. Por una cuestión de economía del lenguaje se habla de "el gen del o para el nepotismo". Así, la acusación según la cual la PE supone una relación de determinación entre un gen y un rasgo constituye un claro ejemplo de la confusión que reina en este debate ${ }^{9}$. En este sentido, deberíamos preguntarnos por qué los psicólogos evolucionistas, cuyo programa consiste en aplicar el modelo de selección natural al análisis de la conducta y la mente humanos, asumirían el determinismo genético, siendo que tal supuesto no es una condición necesaria para la aplicación del modelo de selección a ningún rasgo de ningún organismo, y siendo que dicho supuesto es un caso flagrante de mala biología. La condición para la aplicación del modelo de selección natural es que exista variabilidad heredable para el rasgo analizado. Esto, a su vez, requiere que existan distintas versiones de los genes (alelos) que influyan diferencialmente en el desarrollo del rasgo en cuestión, no que lo determinen (Alcock 2001, 43; Dawkins 2017b, 49 y ss.; Maynard Smith 1997, 524). En el caso que nos ocupa, las evidencias de que los genes influyen en la personalidad y la conducta humana son abrumadores (Harris 2015; Plomin

\footnotetext{
${ }^{9}$ El número y magnitud de estos errores es tal que su refutación demandaría un libro entero. Solo a modo de ejemplo, menciono otros dos errores que aparecen en muchas críticas a la PE. Según el primero de ellos, esta ciencia atribuiría conciencia y otros atributos humanos a los genes. Según el segundo, no tiene sentido sugerir, por ejemplo, que existen diferencias genéticas en relación con la capacidad para leer porque la lectura no formó parte de nuestro amiente evolutivo. El hecho de que estos errores sean tan groseros, y de que se sigan repitiendo, es francamente curioso y demanda, en sí mismo, una explicación. Dejo al lector o a la lectora el ejercicio de argumentar por qué estos cuestionamientos son erróneos.
}

Revista de Humanidades de Valparaíso, 2019, No 14, 187-222 
Perspectivas darwinistas sobre la mente y la conducta humanas: alcances, limitaciones e implicancias educativas

Leonardo González Galli

et al. 2002; Sapolsky 2018). Más adelante reseñaré brevemente un análisis reciente de Steven Pinker sobre la violencia que me permitirá mostrar que la PE de hecho no asume determinismo ni reduccionismo.

Terminaré esta sección con unas palabras sobre la noción de "naturaleza humana". En general, el rechazo de los críticos a este concepto se basa en el supuesto de que el mismo supone que dicha naturaleza consta de una colección de rígidos instintos genéticamente programados. Sin embargo, quienes actualmente hablan de "naturaleza humana" (por ejemplo, Buss 2019 o Pinker 2003) no se refieren a tal cosa porque, tal como expliqué, semejante determinismo es mala biología y es un supuesto innecesario. La "naturaleza humana" podría definirse como el conjunto de rasgos que, estadísticamente, caracterizan a la especie Homo sapiens. Es bastante curioso que alguien niegue totalmente la existencia de tales rasgos universales. El gregarismo, la cultura y el lenguaje son tres ejemplos evidentes de universales humanos. Si reconocemos que estos rasgos son universales, entonces, estamos reconociendo que existe algo así como una "naturaleza humana". A partir de este reconocimiento surge la discusión verdaderamente interesante: ¿Qué otros rasgos son universales y cómo se explica su existencia? (Brown 1999, 2000). Es frecuente también que la afirmación de la existencia de una naturaleza humana se interprete como incompatible con el reconocimiento de la evidente flexibilidad de la conducta humana. Sin embargo, ambos aspectos de lo humano son más bien evidentes: algunos rasgos son casi universales, algo inexplicable si se asume una flexibilidad total, un desarrollo no sesgado ni limitado por el sustrato biológico (determinismo socio-cultural) y, a su vez, todos los rasgos presentan cierta variabilidad, algo inexplicable si se asume un determinismo biológico.

Finalmente, se ha señalado críticamente que la idea de naturaleza humana supone adoptar un enfoque esencialista incompatible con el evolucionismo (Diéguez 2017; 2012). Sin embargo, dicha crítica es otro ejemplo del problema que mencioné antes en relación con la ignorancia por parte de los críticos del carácter estadístico de todas las afirmaciones que se hacen en biología. No existe ninguna esencia inmutable de la especie humana (¡ni de ninguna otra!) sino un conjunto de rasgos que estadísticamente nos permiten caracterizar a nuestra especie. Ontogenéticamente, dichos rasgos son sensibles (en mayor o menor grado según el caso) a las influencias ambientales. Filogenéticamente, dicho conjunto de rasgos es producto del proceso evolutivo y, por lo tanto, no es inmutable. Tal como señala Diéguez (2017), “[...] los rasgos que pueden considerarse como característicos de la naturaleza humana son productos contingentes de la evolución biológica y, por ende, están sujetos a posibles nuevos cambios evolutivos". Del mismo modo, la naturaleza de la especie león se refiere a esa caracterización estadística que podemos encontrar en los libros de zoología. Dicha descripción incluye, por ejemplo, la afirmación de que los leones viven en manadas. Pero, ¿todos los leones son necesariamente gregarios? Seguramente no. Lo más probable es que haya cierta proporción de leones muy poco propensos a la vida en manada. ¿Es entonces incorrecto que el libro de zoología afirme que los leones son gre-

Revista de Humanidades de Valparaíso, 2019, No 14, 187-222

(c) $(1)(9)$ CC BY-NC-ND 
Perspectivas darwinistas sobre la mente y la conducta humanas: alcances, limitaciones e implicancias educativas

Leonardo González Galli

garios? No, no es incorrecto, es solo otra afirmación probabilística más, como todas las afirmaciones de la biología. Nuestra especie no es la excepción: todas las especies tienen su "naturaleza" (Buss 2019, 43). Si no podemos hacer afirmaciones de este tipo sobre nuestra especie no podemos hacerlas sobre ninguna otra $\mathrm{y}$, simplemente, no podríamos decir absolutamente nada sobre los sistemas biológicos.

\subsection{Darwinismo e ideología}

Rechazar a Darwin porque algunas de sus ideas provienen de una analogía con la sociedad capitalista en la cual vivió es, precisamente, la clase de cosa que no deberíamos permitir que nuestros prejuicios nos lleven a hacer.

John Maynard Smith $(1997,523$, traducción propia)

Para los intelectuales [...] resulta muy conveniente creer la gente 'carece de naturaleza', que es completamente maleable. Eso elimina toda barrera moral para la manipulación y el control [...] La doctrina es tan sumamente estúpida que uno ha de buscar una explicación. Esta es la que a mi juicio nos da a entender la historia social e intelectual.

Noam Chomsky (citado en Barsky 2005, 258)

En relación con esta compleja cuestión me limitaré a discutir algunas simplificaciones groseras (pero frecuentes). La acusación de sesgo ideológico esconde varios supuestos relacionados. En primer lugar, se suele señalar que una disciplina es "mala ciencia" y que lo único que explica su existencia es su función ideológica. Pero ¿Por qué una teoría particular funcionaría exclusivamente como sostén de cierta ideología? Aquí lo que se sugiere es que la teoría en cuestión implica intrínsecamente, de algún modo, supuestos propios de la ideología que presuntamente avala y que ello hace que las eventuales aplicaciones o usos de la teoría estén necesariamente sesgados a favor de esa ideología. Examinaré (brevemente, estas cuestiones requerirían un análisis extenso) entonces estas dos cuestiones: ¿Es a PE “mala ciencia”? ¿Favorece de hecho la PE alguna ideología en particular?

Con respecto a la primera cuestión, la PE ha recibido muchas críticas (Buller 2009; McKinnon 2012). A este respecto, cabe preguntarse si es legítimo exigir a esta disciplina estándares epistémicos diferentes de los que se imponen a otras ciencias (Ruse, 1980, 44). Kitcher (1985) ha defendido la necesidad de que aquellas hipótesis que encierran un gran peligro político sean tratadas con más rigor y precaución, y ha señalado que la SB ha fallado en ese punto. Alcock (2001) ha rechazado este doble estándar en cuanto al tratamiento de las diferentes ciencias. Aunque la observación de Kitcher parece razonable, se basa en el supuesto de que las hipótesis biológicas son especialmente peligrosas desde el punto de vista político. Los ejemplos que comentaré más adelante sobre las consecuencias negativas de diversas hipótesis "ambientalistas" (el caso del autismo y el del "efecto Cenicienta") deberían llevarnos a reflexionar sobre la validez de dicho supuesto. 
Perspectivas darwinistas sobre la mente y la conducta humanas: alcances, limitaciones e implicancias educativas Leonardo González Galli

Siguiendo con la crítica de la PE en tanto ciencia, McKinnon $(2012,30)$ cuestiona el uso de ciertas metáforas por parte de los psicólogos evolucionistas como, por ejemplo, la personificación de la selección natural. Sin embargo, dicha metáfora no es más que una expresión de la metáfora del diseño que permea toda la teoría darwiniana (Ruse 2003, 2000). Del mismo modo, esta autora cuestiona el uso de la metáfora computacional de la mente (McKinnon 2012, 36), pero, en este caso, el problema es el mismo, dado que dicha metáfora es fundacional de toda la ciencia cognitiva (Gardner 1988; Pugh 2017). Así, para impugnar la PE sobre estas bases McKinnon debería impugnar también el darwinismo en general y todo el cognitivismo. En relación con los cuestionamientos metodológicos, me limitaré a señalar que la claridad con la que los psicólogos evolucionistas explicitan sus supuestos teóricos y los criterios que utilizan para formular y evaluar sus hipótesis (Alcock 2001, 57 y ss.; Buss 2019, 37 y ss.; Schmitt 2008; Tybur, Miller y Gangestad 2007) no es fácil de encontrar en todos los campos disciplinares.

En cuanto a la posibilidad de que la PE sirva de hecho a una ideología reaccionaria debemos señalar que es innegable que las teorías biológicas, y más específicamente el evolucionismo darwinista, han sido utilizadas para todo tipo de fines políticos (algunos podrían considerase reaccionarios y otros progresistas). Sin embargo, la relación entre estas teorías y esas ideologías dista de ser directa y necesaria (Bowler 2003; Girón Sierra 2005). Para rechazar esta acusación no es necesario adherir a la idea de que las teorías son en sí mismas neutrales y que luego pueden utilizarse de diversos modos (el llamado modelo de la "ciencia martillo", Heler 1996). Podemos reconocer que las teorías se relacionan con las ideologías, por ejemplo, en el sentido de que dichas teorías pueden haber surgido parcialmente de razonamientos analógicos que incluyen ciertos valores no epistémicos. También podría reconocerse que un sesgo ideológico podría estar implicado en el hecho de que una teoría haga más probables ciertas intervenciones en el mundo que otras (Lacey 2005a). Sin embargo, reconocer estos posibles modos de relación entre ciencia e ideología no debería impedirnos reconocer al mismo tiempo el hecho evidente de que suele existir un amplio margen para diversos usos y aplicaciones. Por ejemplo, la genética ha sido utilizada tanto para avalar el racismo como para cuestionarlo. Así, Lewontin (1972) se basó en la genética para cuestionar el concepto tradicional de raza humana ${ }^{10}$. Del mismo modo, entre las aplicaciones de la biología molecular se encuentran tanto los cultivos transgénicos, con diversas consecuencias negativas asociadas, como las técnicas que hicieron posible la identificación de víctimas del terrorismo de Estado (Penchazadeh 2012; Wulff 2014).

Un ejemplo notable de cómo la biología puede tener un efecto progresivo y liberador lo constituye el caso de las explicaciones sobre el autismo. Durante muchos años predominaron explicaciones totalmente ambientalistas de inspiración psicoanalítica (Brose 2009;

${ }^{10}$ Por supuesto, clasificar a la humanidad en razas no es lo mismo que ser racista: el racismo requiere, además, una jerarquización de esas razas.

Revista de Humanidades de Valparaíso, 2019, No 14, 187-222

(c) $(1)(9)$ CC BY-NC-ND 
Perspectivas darwinistas sobre la mente y la conducta humanas: alcances, limitaciones e implicancias educativas

Leonardo González Galli

Hacking 2001; Pollak 2011). Así, psicoanalistas como Bruno Bettelheim y Leon Kanner afirmaron que la principal causa del autismo era una carencia de afecto materno $\mathrm{y}$, en una muestra de crueldad notable, acuñaron incluso el término "madre nevera" para referirse a las madres de niños autistas. No cuesta mucho imaginar el sufrimiento (gratuito, podemos decir retrospectivamente) que estas ideas deben haber generado a miles madres con hijos autistas (además de reforzar los roles de género estereotipados). Luego, la investigación en ciencias biomédicas fue dejando en claro que existen factores estrictamente biológicos (neurológicos, genéticos) implicados en el desarrollo de la condición autista (Brose 2009; Cormand 2015). Según Brose (2009), "Hoy, los padres de los niños autistas han dejado de encontrarse bajo sospecha: las teorías de Kanner y de Bettelheim han sido superadas hace tiempo y rechazadas en múltiples ocasiones". Los estudios biomédicos actuales permiten descartar la hipótesis de que la condición autista esté determinada exclusivamente por factores ambientales y según Brose (2009) actualmente "los médicos consideran el autismo un trastorno congénito de la función cerebral que obedece, sobre todo, a causas genéticas". El "sobre todo" implica que, como siempre, hay lugar para un rol causal de los factores ambientales ${ }^{11}$. Es claro que, en este caso, la aplicación de la biología a lo humano ha tenido un gran efecto liberador.

Hay muchos ejemplos de los costos potenciales de no tener en cuenta la perspectiva biológica sobre lo humano (véase, por ejemplo, Elgarte, 2019 para un análisis de esta cuestión en relación con el diseño de políticas e instituciones). Un caso especialmente interesante, relacionado específicamente con los enfoques darwinistas de lo humano, lo constituye el llamado "efecto Cenicienta". Daly y Wilson (2000) mostraron, con abrumadoras evidencias empíricas, que la presencia en el hogar de un adulto que no sea progenitor biológico, es decir, una madrastra o un padrastro (esta categoría excluye a los padres y madres adoptivos), constituye el factor epidemiológico más importante a la hora de estimar el riesgo de malos tratos graves a menores. Desde la PE se predice que la presencia de padrastros o madrastras sería un factor de riesgo debido a que es esperable que los individuos estén bien predispuestos a invertir recursos en sus descendientes biológicos, pero no en los descendientes de otros individuos. El cuidado de hijos ajenos sería un costo que los individuos estarían obligados a afrontar como consecuencia de formar pareja con personas que ya son padres o madres. La poca predisposición a invertir recursos en hijos ajenos, junto con la obligación de hacerlo debido a que la pareja tiene ya hijos, generaría tensiones que harían más probables todas las formas de maltrato. Desde ya, la explicación que Daly y Wilson dan de este hallazgo es discutida por quienes rechazan toda explicación biológica de lo humano y se han reportado casos en que la predicción de este modelo aparentemente no se cumple (Daly y Wilson 2008; Temrin, Buchmayer y Enquist 2000; Temrin, Nordlund y Sterner 2004). Sin embargo, dado lo dicho en la sección sobre cómo los genes ejercen sus efectos en interacción con el entorno, la eventual comprobación de

${ }^{11}$ Dicho sea de paso, jentre esos factores ambientales no se encuentran las vacunas!

Revista de Humanidades de Valparaíso, 2019, No 14, 187-222

(c) $(9)(9)$ CC BY-NC-ND 
Perspectivas darwinistas sobre la mente y la conducta humanas: alcances, limitaciones e implicancias educativas Leonardo González Galli

alguna excepción no debería sorprender a nadie, y no invalidaría las principales conclusiones de Daly y Wilson. En cualquier caso, parece claro que Daly y Wilson evidenciaron un factor de riesgo principal hasta entonces ignorado (Buss 2019). Esto último ilustra, al menos, el poder heurístico del adaptacionismo aplicado a lo humano y los posibles riesgos de no tener en cuenta dicho enfoque.

Así, el supuesto en que se basa buena parte de la crítica a la PE según el cual las explicaciones biológicas de lo humano tienen necesariamente implicancias políticamente reaccionarias es falso (Tybur, Miller y Gangestad 2007). Por lo tanto, no parece razonable condenar cierta disciplina por el hecho de que haya servido a fines espurios en ciertos contextos. De hecho, si estuviéramos dispuestos a hacer semejante cosa deberíamos condenar a prácticamente a todas disciplinas, incluyendo no solo a las ciencias naturales sino también a las ciencias sociales y la filosofía (Ruse 1980, 113 y ss.). La contracara del supuesto según el cual las explicaciones biológicas de lo humano tienen necesariamente implicancias reaccionarias la constituye el supuesto de que las explicaciones socioculturales tienen necesariamente implicancias progresistas. Sin embargo, la historia muestra que ese no es el caso (Pinker 2003, 229 y ss.). Por ejemplo, el conductismo sirvió de sustento para la tecnología de la propaganda y el adoctrinamiento (a eso se refiere la cita de Chomsky al comienzo de esta sección). Por otro lado, y más allá de los ejemplos antes comentados, no está de más recordar que las hipótesis deberían evaluarse por sus méritos epistémicos con independencia de qué tanto nos simpaticen sus presuntas implicancias ideológicas. Es decir, si una hipótesis bien establecida tuviera implicancias ideológicamente antipáticas deberíamos lidiar con ese hecho.

Hay una cuestión más específica en relación con estos problemas que se refiere a la relación entre el darwinismo en general con la ideología capitalista. En general se reconoce la influencia de los teóricos de la economía política capitalista en Darwin (Bowler 2003; Muñoz 2008; Schweber 2008). Sin embargo, una cosa es reconocer estas relaciones analógicas de influencia recíproca entre dos campos del saber (la economía y la biología) y algo muy distinto es afirmar que el darwinismo no es más que la ideología capitalista proyectada en la naturaleza. Contra esta crítica caben, al menos, tres observaciones. La primera es que este tipo de relaciones analógicas no son exclusivas del darwinismo. En efecto, hoy se reconoce que las metáforas y analogías son una parte esencial de la ciencia en general (Bradie 1999). La segunda es que, a la hora de evaluar la adecuación de una hipótesis debería ser irrelevante qué analogías inspiraron dicha hipótesis, de lo que se trata, en cambio, es de que la hipótesis en cuestión sea puesta a prueba de un modo honesto mediante los procedimientos legitimados por la comunidad de expertos (Ruse 1980, 125-126). La tercera cuestión es que la teoría de la selección natural contiene elementos conceptuales originales que no tienen un análogo evidente en las doctrinas políticas que, parcialmente, le pueden haber servido de inspiración a Darwin. Esta independencia entre ambos campos conceptuales queda en evidencia, por ejemplo, en el hecho de que la teoría darwiniana derivó hacia desarrollos que contradicen directamente algunos aspectos

Revista de Humanidades de Valparaíso, 2019, No 14, 187-222

(c) $(1)(9)$ CC BY-NC-ND 
Perspectivas darwinistas sobre la mente y la conducta humanas: alcances, limitaciones e implicancias educativas

Leonardo González Galli

de la ideología capitalista. Por ejemplo, mientras que la ideología capitalista enfatiza la competencia entre individuos, el darwinismo actual, sobre todo en la perspectiva del "gen egoísta", al poner el foco en los genes no predice que los individuos tengan conductas necesariamente competitivas y egoístas: en la medida en que convenga a los genes, los individuos serán cooperativos y altruistas. Además, si se acepta la hipótesis de selección de grupos (Sober y Wilson 2000) la competencia interindividual pierde aún más peso relativo.

También es pertinente mencionar aquí que la idea de selección natural fue muy rechazada tras ser propuesta por Darwin en 1859. En efecto, aunque Darwin tuvo gran éxito en convencer a la comunidad científica de que las especies evolucionaban, tuvo mucho menos éxito en convencerla de que la selección era el principal mecanismo responsable de dicho cambio. Fue recién con el advenimiento de la Teoría Sintética de la Evolución (alrededor de 1930) que la idea de selección gozó de amplia aceptación. El período que va desde 1859 a 1930, aproximadamente, fue llamado por tal razón "el eclipse del darwinismo" (Bowler 2005, 1985). El hecho de que una teoría que, presuntamente, era tan conveniente para el establishment político fuera rechazada durante tantos años pone en evidencia que la relación entre darwinismo (más específicamente, la selección natural) y capitalismo es más compleja de lo que los críticos sugieren. Esta independencia entre los campos analogados tiene otras implicancias más importantes para esta discusión, en especial el hecho de que la teoría biológica no incluye los aspectos normativos de la teoría de la economía política (Ruse 1980, 124). Finalmente, la eventual aceptación de una de las teorías no implica la validez de la otra. Así, el darwinismo podría ser una excelente teoría sobre la evolución biológica y, al mismo tiempo, el capitalismo podría ser un modo desastroso de concebir la sociedad.

Como ya señalé, nada de lo dicho supone negar que existan relaciones entre la ciencia en general, y la biología en particular, y las ideologías (Alexander y Numbers 2010). Por el contrario, reconocemos que las ciencias (¡todas!) son parte de la sociedad y, por lo tanto, los valores, epistémicos y no epistémicos (si aceptamos tal distinción), influyen en dichas ciencias (Echeverría 2002; Gómez 2014; Lacey 2005a; 2005b). Pero este reconocimiento general no basta para impugnar ningún programa de investigación particular, porque se aplica por igual a todas las ciencias. Por lo tanto, señalar la influencia de la ideología es decir poco y nada. Así, se deberían ofrecer buenas razones para concluir que un programa de investigación no es más que una empresa ideológica. Y mostrar las opiniones personales de cierto autor o algunos casos de usos indebidos no son razones de peso. En los casos particulares, habría que mostrar, por ejemplo, que en cierta disciplina se sostiene alguna hipótesis que resulta epistémicamente inadecuada solo por el hecho de que dicha hipótesis favorece ciertos valores no epistémicos.

Revista de Humanidades de Valparaíso, 2019, No 14, 187-222

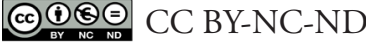


Perspectivas darwinistas sobre la mente y la conducta humanas: alcances, limitaciones e implicancias educativas

Leonardo González Galli

\section{El declive de la violencia según Steven Pinker como caso testigo}

Para apoyar mis argumentos reseñaré brevemente un análisis sobre la violencia del psicolingüista Steven Pinker, unos de los principales autores de la PE.

En uno de sus últimos libros, Pinker (2012) documenta la reducción de diversas formas de violencia y la explica como resultado una interacción entre ciertos cambios socio-culturales y la estructura cognitiva universal cuya existencia postula la PE. Este autor analiza un cambio a nivel conductual, a saber, una reducción de diversas formas de violencia, y como todo psicólogo evolucionista asume que dicho cambio no puede explicarse por un cambio de la estructura cognitiva de base ni de su sustrato genético. Podría terminar aquí la reseña del texto de Pinker y lo poco que he dicho debería alcanzar para que quedara claro que este autor no puede estar incurriendo en determinismo ni reduccionismo genéticos. $\mathrm{Si}$, como pide el reduccionismo y el determinismo, las conductas analizadas se explicaran exclusivamente (reduccionismo) por la existencia de ciertos genes que obligan (determinismo) a la ejecución de dichas conductas, entonces, los niveles de agresión se deberían haber mantenido invariables, dado el escaso número de generaciones abarcado por el período analizado por Pinker. Por el contrario, este autor atribuye este declive de la violencia a cambios socioculturales. Más específicamente, identifica cinco "fuerzas históricas" que serían responsables de este proceso de pacificación. Estas "fuerzas" son: "El Leviatán" (los Estados que monopolizan el uso de la fuerza), el comercio (que generaría un "juego de suma positiva" en el que todos ganan más comerciando que haciendo la guerra), la "feminización" de la sociedad (la importancia creciente de las mujeres en la toma de decisiones), el "cosmopolitismo" (que habría facilitado el ponerse en el lugar de los demás y, de ese modo, ampliar el "círculo solidario") y, por último, la "escalera mecánica de la razón" (que permite evaluar racionalmente las consecuencias de la violencia y considerarla un problema a resolver). Así, Pinker (2012) propone explicaciones basadas en el análisis de la interacción entre ciertos factores socioculturales y una estructura cognitiva universal producto de la selección que excluyen toda forma de reduccionismo o determinismo biológicos.

Por último ¿Es el análisis de Pinker especialmente conveniente para los sectores políticos conservadores? Varios de los factores socioculturales que Pinker identifica como (parcialmente) responsables del declive de la violencia son parte de la agenda política del progresismo clásico. El caso de la creciente participación femenina en la toma de decisiones políticas es un claro ejemplo de ello: no parece que semejante análisis sea conveniente para el patriarcado. Cabe, en este punto, decir algo sobre la idea de "naturalización", una noción frecuentemente asociada a las críticas ya analizadas. Por ejemplo, según McKinnon $(2012,25)$ la PE "[...] ha naturalizado categorías y jerarquías sociales, en particular las de sexo, género y parentesco". Presuntamente, la "naturalización" supondría presentar algo que ha sido "socialmente construido" (Hacking 2001, para un análisis de las complicaciones de la idea de construcción social) como "naturalmente dado". Nuevamente, basta con recurrir al análisis de Pinker para desacreditar esta crítica. Este autor asume que

Revista de Humanidades de Valparaíso, 2019, No 14, 187-222

(c) $(9)(9)$ CC BY-NC-ND 
Perspectivas darwinistas sobre la mente y la conducta humanas: alcances, limitaciones e implicancias educativas Leonardo González Galli

la violencia tiene un fundamento biológico, pero ¿En qué sentido Pinker estaría "naturalizando" la violencia al sugerir que la misma ha disminuido gracias a ciertos cambios sociales en interacción con cierta estructura cognitiva de base biológica? Por el contrario, Pinker está mostrando que los niveles de violencia que una sociedad particular padece son en gran medida consecuencia de los particulares procesos socio-históricos que atravesó dicha sociedad: no parece que eso implique la "naturalización" de nada. Más aún, al identificar esos factores socioculturales y analizar cómo interactúan con la estructura cognitiva humana, Pinker está dando pistas sobre cómo modificar nuestro entorno para tender a una sociedad mejor. Por otro lado, la perspectiva evolucionista continuista aquí adoptada nos invita a desconfiar de la dicotomía natural / no natural. La capacidad de producir cultura es un rasgo propio de nuestra especie, es parte de la naturaleza humana, tan natural como cualquier otro rasgo y, por lo tanto, los productos de la cultura también lo son. En este sentido, si queremos comprender, por ejemplo, el altruismo humano, preguntarse si es natural o no lo es (en tal caso, ¿Sería no-natural, anti-natural, sobre-natural? ¿Qué significan exactamente esas expresiones?) no ayudará en nada a nuestra comprensión. Mejor habríamos, en cambio, en preguntarnos qué factores (tanto genéticos como no genéticos, incluidos los culturales, todos naturales) contribuyen y de qué modo en el desarrollo de ese aspecto de nuestra mente y conducta.

\section{Recapitulación y conclusiones}

En esta sección final recapitularé brevemente mis argumentos para luego analizar algunas de sus implicancias educativas.

El adaptacionismo aplicado a la conducta animal, más específicamente la ecología del comportamiento, constituye un programa de investigación muy activo desde hace unos cuarenta años. No se trata de un área de investigación marginal ni de un programa idiosincrático de uno o dos autores. Dado este contexto, y aceptando que nuestra especie tiene un origen evolutivo, lo más razonable es asumir que el adaptacionismo tiene, legítimamente, mucho para decir sobre nuestra mente y conducta. Así, solo la adopción de un enfoque abiertamente excepcionalista, en el que se asuma un hiato entre nosotros y el resto de las especies, nos permitiría excluir a priori a nuestra especie de este tipo de análisis. El análisis de Schaeffer (2009), presentado en la sección 2.1, me lleva a rechazar esas pretensiones excepcionalistas. Por otro lado, muchos autores están bien dispuestos a recurrir al adaptacionismo cuando de explicar la anatomía y fisiología humanas se trata, pero, sin embargo, consideran que dicho enfoque no es legítimo ni pertinente cuando lo que estamos analizando es la mente o la conducta. Dicha distinción supone adherir a un dualismo difícil de sostener desde una perspectiva naturalista: la conducta y la mente son funciones de un sistema fisiológico-anatómico influido (no determinado) por los genes y que, por lo tanto, debe haber evolucionado por selección natural. En síntesis, el rechazo de la tesis de la excepcionalidad humana y la adopción de una perspectiva evolucionista

Revista de Humanidades de Valparaíso, 2019, No 14, 187-222

(c) $(1)(9)$ CC BY-NC-ND 
Perspectivas darwinistas sobre la mente y la conducta humanas: alcances, limitaciones e implicancias educativas

Leonardo González Galli

nos lleva a asumir la pertinencia y legitimidad del enfoque adaptacionista aplicado a la mente y la conducta humanas. Actualmente, son la psicología evolucionista y la ecología del comportamiento humano los programas de investigación que encarnan dicho enfoque. Así, eventualmente, lo que requiere una argumentación especial no es la aplicación de esta perspectiva a nuestra especie sino su rechazo a priori.

Por otro lado, muchos autores (y educadores) denuncian que la PE (como el resto de las disciplinas biológicas aplicadas a lo humano) constituye un caso de reduccionismo biológico y determinismo genético. Además, se trataría de "mala ciencia" al servicio de una ideología reaccionaria. En relación con estas críticas intenté mostrar que los modelos teóricos en que se fundamenta la PE no suponen reduccionismo ni determinismo y que no puede afirmarse que haya una relación fuerte, necesaria o evidente entre dicha disciplina y una ideología en particular. Por otro lado, la perspectiva semántica de las teorías científicas (Giere 2006) supone que ninguna teoría puede pretender ofrecer una explicación total de un fenómeno y que, por lo tanto, la comprensión de cualquier fenómeno demanda un pluralismo teórico que excluye por principio toda forma de reduccionismo. El enfoque adaptacionista aplicado a la mente y la conducta humanas solo puede, por lo tanto, captar ciertos aspectos de dichos fenómenos desde una perspectiva particular. Estas afirmaciones valen para todo modelo científico, más allá de las pretensiones de algunos autores particulares. La perspectiva semántica nos recuerda, además, que lo importante de una teoría es qué dicen sus modelos sobre el mundo. En relación con esta cuestión, el principal modelo en que se basa la PE es la selección natural, modelo que tiene entre sus supuestos el de variabilidad heredable. Dicho supuesto implica asumir que los genes influyen en el desarrollo de los rasgos analizados, no que lo determinan. De hecho, tal como ya analicé in extenso, la idea misma de determinación genética es simplemente incompatible con todo lo que sabemos de biología. Ninguno de los modelos más específicos en que se basa la PE, por ejemplo, el de una mente modular, implica tampoco ninguna relación de determinación genética.

En síntesis, el rechazo de la tesis de la excepción humana y la adopción de una perspectiva evolucionista y de un enfoque semántico sobre las teorías científicas me llevan a concluir que el adaptacionismo encarnado por la PE es un enfoque teórico legítimo y prometedor para aportar a la comprensión de ciertos aspectos de la mente y la conducta humanas, y que no implica una perspectiva reduccionista y determinista ni un sesgo ideológico particular. Permitiéndome un pequeño ejercicio de normativismo epistemológico diré que sería deseable que los propios científicos, tanto aquellos que aplican la biología a lo humano como aquellos que cuestionan dicho programa, comprendieran que sus eventuales pretensiones de explicaciones totales no tienen mayor sustento y que reconocieran explícitamente que sus aproximaciones son necesariamente perspectivas (Giere 2006). Todos ganaríamos en esta discusión si reconociéramos lo limitado del propio enfoque (sea cual fuere) y la necesidad del pluralismo teórico, ajustando nuestros discursos en consecuencia.

Revista de Humanidades de Valparaíso, 2019, No 14, 187-222

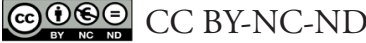


Perspectivas darwinistas sobre la mente y la conducta humanas: alcances, limitaciones e implicancias educativas Leonardo González Galli

Para concluir este trabajo quisiera volver a las preocupaciones que motivaron su escritura. Tal como señalé antes, en el ámbito educativo (la investigación en didáctica de la biología y las prácticas educativas) impera actualmente una perspectiva "socioculturalista" antibiológica que lleva a rechazar todo enfoque biológico de lo humano. En la práctica, esta perspectiva se traduce en una de dos actitudes por parte de docentes e investigadores: la no mención de las perspectivas darwinianas de lo humano o su mención y condena sin matices. Como ejemplo de la primera actitud, si revisamos textos recientes de didáctica de la biología evolutiva tales como Understanding evolution (Kampourakis 2014) o Evolution challenges (Rosengren et al. 2012) no encontramos ni una sola mención a la PE o la EC humana. Como ejemplo de la segunda actitud, De Vecchi y Giordan (2006, 43-44) reiteran las críticas aquí discutidas y, lo que es un notable sinsentido, emparentan la SB con el racismo. La asociación de la SB, que afirma una unidad biológica de la especie humana, con el racismo, que afirma exactamente lo contrario, no es más que otra muestra de la confusión que reina en estos debates. Tal como señala David S. Wilson $(2010,12)$, “Algunos intelectuales emulan a los 'creacionistas de la Tierra joven' en su rechazo a la evolución cuando se llega a los asuntos humanos". Este rechazo en la comunidad educativa de toda perspectiva biológica de lo humano obedece, sin dudas, a múltiples factores. La experiencia personal sugiere que entre dichos factores se encuentra la gran prédica que han tenido entre el profesorado los textos de Stephen Gould y Richard Lewontin. Muchos se han formado una imagen de la SB humana, la PE y la EC humana exclusivamente a partir de los textos de estos críticos (entre dichos textos se destacan, Gould 2010, 1997 y Lewontin, Rose y Kamin 1996).

Ahora bien ¿Por qué considero que es un problema que esta sea la perspectiva dominante sobre estos temas en el ámbito educativo? Por, al menos, dos razones. En primer lugar, por una razón básica: dicha perspectiva asume todos los supuestos que he cuestionado en este trabajo, por lo que en ningún caso puede ser positivo asumirla. En segundo lugar, por una razón específicamente didáctica. Para decirlo brevemente, sugeriré que el mejor modo de fomentar el pensamiento crítico en los estudiantes en relación con temas complejos como estos es abordar directamente el estudio de los modelos científicos implicados, así como su aplicación a los casos más peliagudos. Más allá de lo que realmente impliquen los modelos científicos que he analizado, no hay dudas de que en la comunicación de estos temas al público general es frecuente un discurso biologicista. Por lo tanto, es razonable que uno de los objetivos de la enseñanza general obligatoria sea ayudar a los estudiantes a cuestionar dicho biologicismo (Castéra y Clément 2012; Jiménez Aleixandre 2012). Acuerdo plenamente con dicho objetivo. El desacuerdo radica en cuál es el mejor modo de alcanzar dicho objetivo. Como ya señalé, muchos educadores ignoran totalmente la aplicación de la biología a los asuntos humanos o bien limitan el abordaje del tema a denunciar como mala ciencia ideológicamente sesgada dicha aplicación. Sin embargo, la primera estrategia deja a los estudiantes indefensos frente a los discursos biologicistas tan frecuentes en los grandes medios de comunicación. La segunda estra- 
Perspectivas darwinistas sobre la mente y la conducta humanas: alcances, limitaciones e implicancias educativas Leonardo González Galli

tegia, por su parte, solo deja a los estudiantes, como única mirada posible de lo humano, una perspectiva socioculturalista, tan reduccionista y determinista como el biologicismo. Desde ya, quienes adoptan esta segunda estrategia no ven problema alguno en esta consecuencia porque, como ya he comentado (y cuestionado), asumen que el socioculturalismo tiene necesariamente implicancias políticas progresistas.

Por el contrario, un tratamiento educativo adecuado de estos temas en las clases podría contribuir a la formación de ciudadanos que pudieran analizar críticamente los mensajes, esta vez sí, reduccionistas y deterministas, que reciben desde los medios de comunicación. Ese "tratamiento educativo adecuado" debería implicar dos cuestiones, la primera científica y la segunda metacientífica: (1) ayudar a los estudiantes a comprender qué dicen y qué no dicen, qué explican y qué no explican, los modelos teóricos en cuestión y (2) ayudar a los estudiantes a comprender que cualquier modelo solo puede iluminar ciertos aspectos y desde ciertas perspectivas del fenómeno analizado y que, por lo tanto, es imprescindible adoptar un pluralismo teórico. El primer punto supone un sólido aprendizaje de los modelos científicos y un análisis profundo de su aplicación a lo humano. Esto se debe a que es ingenuo creer que un modelo aprendido a partir de casos paradigmáticos como el melanismo industrial o el cuello de las jirafas luego podrá ser aplicado con éxito por los estudiantes a casos tales como la conducta humana. Por su parte, el segundo punto demanda un análisis explícito de la naturaleza de los modelos científicos (en relación con este punto considero especialmente adecuado el enfoque semántico que ya he comentado).

Sugiero entonces que una adecuada discusión de qué dice la PE (o la genética o las neurociencias) sobre nuestra mente y conducta ayudaría a que los estudiantes detectaran las distorsiones de las versiones pop de estas teorías y pondría en evidencia las limitaciones de dichas perspectivas. Por otro lado, la comprensión de qué no explica la biología ayudaría a comprender la necesidad de otras explicaciones complementarias ofrecidas por disciplinas como las ciencias sociales. Solo quien comprende qué dice un modelo puede comprender qué aspectos del mundo no son explicados por dicho modelo. Así, lo que podría prevenir la difusión y consolidación de los discursos reduccionistas y deterministas no es la evitación de la biología aplicada a lo humano sino, por el contrario, la apropiación crítica de dichos marcos teóricos. Y tal apropiación no tendrá lugar mientras en el ámbito educativo domine una actitud de rechazo acrítico y sin matices de estos enfoques.

En síntesis, la formación de ciudadanos/as críticos/as requiere que se les enseñe con rigor y libertad lo que todos los modelos científicos vigentes tienen para decir sobre lo humano. Esto implica, además, discutir explícitamente las controversias asociadas a dichos modelos. Por el contrario, la actitud que muchos docentes adoptan, basados en las críticas de los enfoques biológicos que aquí he cuestionado, constituyen una forma de adoctrinamiento, es decir, exactamente lo contrario de una formación para una ciudadanía crítica. Dada la complejidad del tema, cada docente deberá evaluar en qué cursos es viable introducir estas discusiones. En cualquier caso, considero que estos temas no pueden ser

Revista de Humanidades de Valparaíso, 2019, No 14, 187-222

(c) $(1)(9)$ CC BY-NC-ND 
Perspectivas darwinistas sobre la mente y la conducta humanas: alcances, limitaciones e implicancias educativas Leonardo González Galli

eludidos en la formación del profesorado de biología y de biólogos. Espero que este texto contribuya a la reflexión de docentes e investigadores en relación con cómo introducimos, o no lo hacemos, estos temas en las aulas.

\section{Agradecimientos}

El autor agradece al Consejo Nacional de Investigaciones Científicas y Técnicas (CONICET) y a la Universidad de Buenos Aires (Proyecto UBACyT 20020170200207BA) por el apoyo financiero. También agradece especialmente al Dr. Santiago Ginnobili y al Mg. Joaquín Suárez por la lectura crítica del artículo y las pertinentes sugerencias realizadas.

\section{Referencias bibliográficas}

Alcock, J. (2001). The Triumph of Sociobiology. Oxford: Oxford University Press.

Alexander, D., Numbers, R. (eds.) (2010). Biology and Ideology from Descartes to Dawkins. Chicago: The University of Chicago Press.

Barsky, R. (2005). Noam Chomsky. Una vida de discrepancia. Barcelona: Península.

Bautista, L., Fernández-Juricic, E. (2016). Optimización del comportamiento. En J. Carranza (ed.), Etología adaptativa. El comportamiento como producto de la selección natural, pp. 155-194. Córdoba: Editorial Universidad de Córdoba / Universidad de Extremadura.

Bergstrom, C., Dugatkin, L. A. (2012). Evolution. Nueva York: W. W. Norton \& Company.

Bowler, P. (1985). El eclipse del darwinismo. Teorías evolucionistas antidarwinistas en las décadas en torno a 1900. Barcelona: Labor.

Bowler, P. (2003). Evolution. The History of an Idea. Berkeley: University of California Press.

Bowler, P. (2005). Revisiting the Eclipse of Darwinism. Journal of the History of Biology, 38(1): 19-32. doi: 10.1007/s 10739-004-6507-0

Bradie, M. (1999). Science and metaphor. Biology and Philosophy, 14(2): 159-166. doi: https:// doi.org/10.1023/A:1006601214943

Brown, D. (1999). Human universals. En R. Wilson, F. Keil (eds.), The MIT Encyclopedia of the Cognitive Sciences, pp. 382-384. Cambridge: The MIT Press.

Brown, D. (2000). Human Universals and their Implications. En N. Roughley (ed.), Being Humans. Anthropological Universality and Particularity in Transdisciplinary Perspectives, pp. 156-174. Berlin: de Gruyter.

Buller, D. (2007). Varieties of Evolutionary Psychology. En D. Hull, M. Ruse (eds.), The Cambridge Companion to The Philosophy of Biology, pp. 255-274. Cambridge: Cambridge University Press.

Revista de Humanidades de Valparaíso, 2019, No 14, 187-222

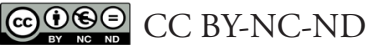


Perspectivas darwinistas sobre la mente y la conducta humanas: alcances, limitaciones e implicancias educativas Leonardo González Galli

Buller, D. (2009). Cuatro falacias de la psicología evolutiva popular. Investigación y Ciencia, 388: 58-65.

Buss, D. (2019). Evolutionary psychology. The New Science of the Mind. Nueva York: Routledge.

Brose, N. (2009). Autismo. Mente y Cerebro, 38: 36-41.

Carranza, J. (ed.) (2016). Etología adaptativa. El comportamiento como producto de la selección natural. Córdoba: Editorial Universidad de Córdoba / Universidad de Extremadura.

Castéra, J., Clément, P. (2012). Teachers' Conceptions About the Genetic Determinism of Human Behaviour: A Survey in 23 Countries. Science \& Education, 23(2): 417-443. doi:10.1007/ s11191-012-9494-0

Castro, L., López-Fanjul, C., Toro, M. A. (2003). A la sombra de Darwin. Las aproximaciones evolucionistas al comportamiento humano. Madrid: Siglo XXI.

Cormand, B. (2015). El paisaje genético del autismo. Mente y Cerebro, 72: 44-46.

Daly, M., Wilson, M. (2000). La verdad sobre Cenicienta. Una aproximación darwiniana al amor parental. Barcelona: Crítica.

Daly, M. y Wilson, M. (2008). Is "Cinderella Effect" Controversial? A Case Study of Evolution-Minded Research and Critiques Thereof. En C. Crawford, D. Krebs (eds.), Foundations of evolutionary psychology, pp. 383-400. Nueva York: Taylor \& Francis Group/ Lawrence Erlbaum Associates.

Darwin, C. (1876). The Origin of Species by Means of Natural Selection or the Preservation of Favoured Races in the Struggle fot Life. Sixth Edition with Addittions and Corrections to 1872. Londres: John Murray.

Davies, N., Krebs, J., West, S. (2012). An Introduction to Behavioral Ecology. Chichester: Wiley-Blackwell.

Dawkins, R. (2017a). El gen egoista extendido. Edición especial $40^{\circ}$ aniversario. Madrid: Salvat.

Dawkins, R. (2017b). El fenotipo extendido. El largo alcance del gen. Madrid: Capitán Swing.

De la O-Rodríguez, C., Montoya, B. (2011). Biología del comportamiento animal: la etología como un puente en el estudio del comportamiento. En G. Gutiérrez, M. Papini (eds.), Darwin y las ciencias del comportamiento, pp. 137-158. Bogotá: Universidad Nacional de Colombia / Colegio Colombiano de Psicólogos.

De Vecchi, G., Giordan, A. (2006). Guía práctica para la enseñanza científica. Sevilla: Díada.

De Waal, F. (2000). Bases genéticas y ambientales de la conducta. Investigación y Ciencia, 280: 48-53.

Dennett, D. (1995). Darwin's dangerous idea: Evolution and the meanings of Life. Nueva York: Simon and Schuster.

Diéguez, A. (2012). La vida bajo escrutinio. Una introducción a la filosofia de la biología. Barcelona: Buridán.

Revista de Humanidades de Valparaíso, 2019, No 14, 187-222

(c) (1) @ $\odot$ CC BY-NC-ND 
Perspectivas darwinistas sobre la mente y la conducta humanas: alcances, limitaciones e implicancias educativas Leonardo González Galli

Diéguez, A. (2017). Transhumanismo y naturaleza humana. Contribuciones a congresos científicos. Universidad de Málaga. URL: https:/riuma.uma.es/xmlui/bitstream/handle/10630/14245/Resumen\%20Transhumanismo\%20y\%20naturaleza\%20humana.pdf?sequence $=3 \&$ isAllowed $=\mathrm{y}$

Díez, J., Moulines, C. U. (2008). Fundamentos de filosofía de la ciencia. Barcelona: Ariel.

Dobzhansky, T., Ayala, F., Stebbins, G., Valentine, J. (1980). Evolución. Barcelona: Omega.

Echeverría, Javier (2002). Ciencia y valores. Barcelona: Destino.

Elgarte, J. (2019) Usos legítimos y necesarios de la ciencia en el diseño de políticas e instituciones: algunos ejemplos. En D. Busdygan (coord.), Rostros del igualitarismo: discusiones y desafíos filosóficos. Buenos Aires: Teseo Press. En prensa.

Futuyma, D., Kirkpatrick, M. (2018). Evolution. Oxford: Oxford University Press.

Gardner, H. (1988). La nueva ciencia de la mente. Historia de la revolución cognitiva. Barcelona: Paidós.

Giere, R. (1992). La explicación de la ciencia. Ciudad de México: Consejo Nacional de Ciencia y Tecnología.

Giere, R. (2006). Scientific Perspectivism. Chicago: The University of Chicago Press.

Girón Sierra, A. (2005). Darwinismo, darwinismo social e izquierda política (1859-1914). Reflexiones de carácter general. En M. Miranda, M., G. Vallejo (comp.), Darwinismo social y eugenesia en el mundo latino, pp. 23-58. Buenos Aires: Siglo XXI de Argentina Editores.

Gómez, R. (2014). La dimensión valorativa de las ciencias. Bernal: Universidad Nacional de Quilmes Editorial.

Gould, S. (1997). La falsa medida del hombre. Barcelona: Crítica.

Gould, S. (2010). Desde Darwin. Reflexiones sobre historia natural. Barcelona: Crítica.

Gould, S., Lewontin, R. (1979). The spandrels of San Marco and the Panglossian paradigm: a critique of the adaptationist programme. Proceedings of the Royal Society of London. B. doi: http://doi.org/10.1098/rspb.1979.0086

Hacking, I. (2001). ¿La construcción social de qué? Barcelona: Paidós.

Harris, J. (2015). No hay dos iguales, Individualidad humana y naturaleza humana. Madrid: Editorial Funambulista.

Heler, Mario (1996). Ética y ciencia: la responsabilidad del martillo. Buenos Aires: Biblós.

Jiménez Aleixandre, M. (2012). Determinism and Underdetermination in Genetics: Implications for Students' Engagement in Argumentation and Epistemic Practices. Science \& Education, 23(2): 465-484. doi: 10.1007/s11191-012-9561-6

Kampourakis, K. (2014). Understanding evolution. Nueva York: Cambridge University Press.

Kitcher, P. (1985). Vaulting Ambition: Sociobiology and the Quest for Human Nature. Cambridge: The MIT Press.

Revista de Humanidades de Valparaíso, 2019, No 14, 187-222

(c) (1)@९ CC BY-NC-ND 
Perspectivas darwinistas sobre la mente y la conducta humanas: alcances, limitaciones e implicancias educativas Leonardo González Galli

Lacey, H. (2005a). Values and Objectivity in Science. The Current Controversy about Transgenic Crops. Lanham: Lexington Books.

Lacey, H. (2005b). Is science value free? Values and scientific understanding. Nueva York: Taylor $\&$ Francis.

Laland, K., Galef, B. (ed.) (2009). The Question of Animal Culture. Cambridge: Harvard University Press.

Lewens, T. (2007). Adaptation. En D. Hull, M. Ruse (eds.), The Cambridge Companion to The Philosophy of Biology, pp. 1-21. Cambridge: Cambridge University Press.

Lewontin, R. (1972). The apportionment of human diversity. En T. Dobzhansky, M. Hecht, W. Steere (eds.), Evolutionary Biology, 6: 381-398. New York: Appleton-Century-Crofts.

Lewontin, R. (1978). Adaptation. Scientific American, 239(3): 212-230.

Lewontin, R., Rose, S., Kamin, L. (1996). No está en los genes. Críticas del racismo biológico. Barcelona: Grijalbo.

Lorenz, K. (1986). Fundamentos de etología. Estudio comparado de las conductas. Barcelona: Paidós.

Maynard, S. J. (1997). Commentary. En P. Gowaty (ed.), Feminism and Evolutionary Biology, pp. 522-526. Nueva York: Chapman \& Hall.

Mayr, E. (1998). Así es la biología. Madrid: Debate.

Mayr, E: (2006). Por qué es única la biología. Consideraciones sobre la autonomía de una disciplina cientifica. Buenos Aires: Katz.

Meaney, M. (2006). Nature, Nurture, and the Disunity of Knowledge. Annals of the New York Academy of Sciences, 935(1): 50-61. doi:10.1111/j.1749-6632.2001.tb03470.x

McKinnon, S. (2012). Genética neoliberal. Mitos y moralejas de la psicología evolucionista. Ciudad de México: Fondo de Cultura Económica.

Muñoz, J. (2008). El concepto darwiniano de escasez: la extensión de la ideología capitalista al mundo vivo. En J. Llorente, R. Ruiz, G. Zamudio, R. Noguera, R. (comp.), Fundamentos históricos de la biología, pp. 617-638. Ciudad de México: Universidad Nacional Autónoma de México.

Penchazadeh, V. (comp.) (2012). Genética y derechos humanos. Encuentros y desencuentros. Buenos Aires: Paidós.

Pinker, S. (2003). La tabla rasa. La negación moderna de la naturaleza humana. Barcelona: Paidós.

Pinker, S. (2012). Los ángeles que llevamos dentro. El declive de la violencia y sus implicancias. Barcelona: Paidós.

Pinker, S. (2000). Cómo funciona la mente. Barcelona: Destino.

Revista de Humanidades de Valparaíso, 2019, No 14, 187-222

(c) $(1)(9)$ CC BY-NC-ND 
Perspectivas darwinistas sobre la mente y la conducta humanas: alcances, limitaciones e implicancias educativas Leonardo González Galli

Plomin, R., Defries, J., McClearn, G., Mcguffin, P. (2002). Genética de la conducta. Barcelona: Ariel.

Pollak, R. (2011). Bettelheim, el impostor. En C. Meyer (dir.); M. Borch-Jacobsen, J. Cottraux, D. Pleux, V. Rillauer (eds.), El libro negro del psicoanálisis. Vivir, pensar y estar mejor sin Freud, pp. 409-419. Buenos Aires: Sudamericana.

Pugh, K. (2017). Computers, Cockroaches, and Ecosystems: Understanding Learning through Metaphor. Charlotte: Information Age Publishing.

Ridley, M. (2004). Qué nos hace humanos. Ciudad de México: Santillana.

Rose, H., Rose, S. (eds.) (2000). Alas. Poor Darwin. Arguments Against Evolutionary Psychology. Londres: Vintage. Random House.

Rosengren, K., Brem, S., Evans, E. M., Sinatra, G. (eds.) (2012). Evolution Challenges. Integrating research and practice in teaching and learning about evolution. New York: Oxford University Press.

Ruse, M. (1980). Sociobiología. Madrid: Cátedra.

Ruse, M. (2000). Teleology: Yesterday, today, and tomorrow? Studies in History and Philosophy of Biological \& Biomedical Sciences, 31(1): 213-232.

Ruse, M. (2003). Darwin and design. Does evolution have a purpose? Cambridge: Harvard University Press.

Sapolsky, R. (2007). El mono enamorado y otros ensayos sobre nuestra vida animal. Barcelona: Paidós.

Sapolsky, R. (2018). Compórtate. La biología que hay detrás de nuestros mejores y peores comportamientos. Madrid: Capitán Swing Libros.

Schaeffer, J. M. (2009). El fin de la excepción humana. Buenos Aires: Fondo de Cultura Económica.

Schmitt, D. (2008). Evolutionary Psychology Research Methods. En C. Crawford, D. Krebs (eds.), Foundations of evolutionary psychology, pp. 215-238. Nueva York: Taylor \& Francis Group/Lawrence Erlbaum Associates.

Schweber, S. (2008). Darwin y los economistas políticos: la divergencia de caracteres. En J. Llorente, R. Ruiz, G. Zamudio, R. Noguera (comp.), Fundamentos históricos de la biología, pp. 533-616. Ciudad de México: Universidad Nacional Autónoma de México.

Sober, E., Wilson, D. S. (2000). El comportamiento altruista. Evolución y psicología. Madrid: Siglo XXI.

Soler, M. (2009). Adaptación del comportamiento: comprendiendo al animal humano. Madrid: Síntesis.

Temrin, H., Buchmayer, S. Enquist, M. (2000). Step-parents and infanticide: new data contradict evolutionary predictions. Proc. Biol. Sci., 267(1446): 943-945. doi: 10.1098/rspb.2000.1094

Revista de Humanidades de Valparaiso, 2019, No 14, 187-222

(c) $(1)(9)$ CC BY-NC-ND 
Perspectivas darwinistas sobre la mente y la conducta humanas: alcances, limitaciones e implicancias educativas Leonardo González Galli

Temrin, H., Nordlund, J., Sterner, S. (2004). Are stepchildren overrepresented as victims of lethal parental violence in Sweden? Proceedings of the Royal Society of London B, 271(3): S124-S126.

Thorpe, William (1982). Breve historia de la etología. Madrid: Alianza.

Tinbergen, Niko (1985). El estudio del instinto. Ciudad de México: Siglo XXI.

Trivers, R. (1971). The evolution of reciprocal altruism. Quarterly Review of Biology, 46: 35-57. doi: $10.1086 / 406755$

Trivers, R. (1972). Parental investment and sexual selection. En B. Campbell (ed.), Sexual selection and the descent of man: 1871-1971, pp. 136-179. Chicago: Aldine.

Tybur, J., Miller, G., Gangestad, S. (2007). Testing the Controversy: An Empirical Examination of Adaptationists' Attitudes Toward Politics and Science. Human Nature, 18(4): 313-28. doi: 10.1007/s12110-007-9024-y

Williams, G. (1966). Adaptation and natural selection; a critique of some current evolutionary thought. Princeton, N.J.: Princeton University Press.

Wilson, D. S. (2010). Evolución para todos. De cómo la teoría de Darwin cambia nuestro pensar. Xalapa: Universidad Veracruzana.

Wilson, E. (1980). Sociobiología. La nueva síntesis. Barcelona: Omeba.

Wulff, G. (2014). Las abuelas y la genética. El aporte de la ciencia en la búsqueda de los chicos desaparecidos. Buenos Aires: Abuelas de Plaza de Mayo. 